\title{
Nano- and Macrotribological Properties of Nanoperiod Multilayer Films Deposited by Bias Sputtering
}

\author{
Shojiro Miyake ${ }^{1}$ and Mei Wang ${ }^{2}$ \\ ${ }^{1}$ Department of Innovative System Engineering, Nippon Institute of Technology, Saitama 345-8501, Japan \\ ${ }^{2}$ Department of Research and Development, OSG Corporation, Aichi 442-8544, Japan
}

Correspondence should be addressed to Mei Wang,wmei64@yahoo.com

Received 8 December 2011; Accepted 21 February 2012

Academic Editor: Arturo I. Martinez

Copyright ( 2012 S. Miyake and M. Wang. This is an open access article distributed under the Creative Commons Attribution License, which permits unrestricted use, distribution, and reproduction in any medium, provided the original work is properly cited.

\begin{abstract}
Carbon and boron nitride nanoperiod $(\mathrm{C} / \mathrm{BN}) \mathrm{n}$, boron nitride and carbon $(\mathrm{BN} / \mathrm{C}) \mathrm{n}$, carbon nitride and boron nitride nanoperiod $(\mathrm{CN} / \mathrm{BN}) \mathrm{n}$, and boron nitride and carbon nitride $(\mathrm{BN} / \mathrm{CN}) \mathrm{n}]$ multilayer films with a 4-nm-period multilayer structure were deposited by bias radio frequency (RF) sputtering. The substrate used for deposition was repeatedly positioned opposite graphite and boron nitride targets. Both the nanoindentation hardness and microwear resistance of the multilayer $(\mathrm{CN} / \mathrm{BN}) \mathrm{n}$ and $(\mathrm{BN} / \mathrm{CN}) \mathrm{n}$ films changed with the layer period. The multilayer films with a $4 \mathrm{~nm}$ period had the highest hardness and microwear resistance. The processing characteristics of the $(\mathrm{C} / \mathrm{BN}) \mathrm{n}$ and $(\mathrm{BN} / \mathrm{C}) \mathrm{n}$ films with a 4 -nm-period multilayer structure were investigated using a conductive atomic force microscope (AFM) with force modulation, which permits the quantitative recording of current and frictional force as functions of applied force. The results of processing indicated that friction and surface-current measurements are effective methods of investigating multilayer nanostructural surfaces and that the method proposed in this study for micro-electro-mechanical processing systems has high precision.
\end{abstract}

\section{Introduction}

There has been continuing interest in the deposition of nanoperiod multilayer films [1]. For example, hard carbon and titanium nitride multilayer films have been deposited $[1,2]$. The internal energy of such multilayer films changes with nanoscale changes to their structure, resulting in their hardness being significantly increased. Moreover, it was clarified that the mechanical properties of multilayer films are improved by the formation of interfaces between the periodic layers [3]. For these nanoperiod multilayer films, the mechanism of hardness enhancement is based on the reduced probability of dislocations between the periodic layers or on the formation of a composite layer between the periodic layers $[3,4]$.

In the tribological application of thin films, to improve wear resistance, superhard films composed of boron, carbon, and nitrogen have attracted considerable attention in recent years as it is known that boron, carbon, and nitrogen can be used as basic component elements. It is also expected that such films can be used as solid lubricant films with superlow friction coefficients to improve the lubricant properties of surfaces. Superlattice films laminated with thin layers with a thickness of several nanometers have been investigated. Concretely, for use as superhard films, investigations on superlattice films such as $\mathrm{CNx} / \mathrm{TiN}$ and TiN/AlN have been realized $[5,6]$. A superhard, wear-resistant, and low-friction film instead of a conventional solid lubricant film is desired for reducing atomic-scale wear and the fluctuation of friction force [7]. Some candidates of superhard films are made of diamond $[8,9]$, carbon nitride $[10]$, and $\mathrm{cBN}[11]$, which have microwear resistance and low friction. These superhard films are composed of $\mathrm{B}, \mathrm{C}$ and $\mathrm{N}$, three neighboring elements in the periodic table.

In our previous study, 2-, 4-, and 8-nm-period multilayer $(\mathrm{C} / \mathrm{BN}) \mathrm{n}$ layers were prepared $[12,13]$. Both micro-vickers and nanoindentation hardness of a 4-nm-period $(\mathrm{C} / \mathrm{BN}) \mathrm{n}$ multilayer film were the highest of all period $(\mathrm{C} / \mathrm{BN}) \mathrm{n}$ films. The improvement effects of the 4-nm-period $(\mathrm{C} / \mathrm{BN}) \mathrm{n}$ multilayer film on the decrease of the friction coefficient and 
damage of the wear surface were significantly remarkable and evaluated in both of the reciprocation and ball on disk type tribo tests [13]. Furthermore, nanoperiod carbon nitride and boron nitride $(\mathrm{CN} / \mathrm{BN}) \mathrm{n}$ multilayer films were deposited on silicon wafers to increase the hardness of the substrates [4]. Compared with the 2- and 8-nm-period (CN/BN)n multilayer films, the 4-nm-period multilayer films were found to have higher nanoindentation hardness and a lower modulus of dissipation $[4,14]$. The dependence of atomic-scale wear properties on the number of sliding cycles indicated that wear resistance increased at the interface between the carbon nitride and boron nitride layers of the multilayer films [4, 14]. Superlattice structures of these nanoperiod $(\mathrm{C} / \mathrm{BN}) \mathrm{n}$ and $(\mathrm{CN} / \mathrm{BN}) n$ layers were obtained by layering two or more materials in a regular periodic structure with a thickness of 10-30 atomic layers. Such layering resulted in a marked increase in internal energy, as well as in elastic modulus, hardness, and other mechanical properties, to produce improved performance and characteristics compared with those of individual single-layer materials [14]. Since the microstructure formation of multilayer coatings is strongly affected by the local interaction of atoms deposited on the surface, details of the atom-surface interaction and the interface clearly play a crucial role in atomic nanoprocessing, although the explicit behavior of such properties has not yet been investigated. Therefore, an understanding of the surface morphology of a processed area is very important for investigating the fundamental characteristics of the microstructure of multilayers in order to improve processing.

The atomic force microscope (AFM) is a powerful tool for investigating the topography of sample surfaces on the atomic scale. Several attempts have also been made to examine the nanometer-scale processing of surfaces using an AFM. Surface modification techniques have been developed on the basis of AFM, which could conceivably be used as the writing mechanism in a storage device. If this could be practically achieved, such a device would offer enormous advantages over current storage technology in terms of area density. It would also potentially be a low-cost technology [15]. In this technique, the tip of an AFM cantilever is placed in contact with a moving surface. The substrate material is a polymer, and writing is carried out by heating the tip [16]. The heated tip softens the polymer surface, and the pressure creates a small pit. A new micromechanical approach based on an AFM that combines high density with reasonable data rates has been proposed [17].

On the other hand, the electrical resistance of materials is one of the physical quantities most sensitive to the physical and chemical structures of materials. However, one problem with the measurement of electrical resistance is that it leads to a lack of understanding of the local structure and electrical properties of multilayers on the nanometer scale. This is particularly due to nanoperiod multilayer films with complex microstructures. Scanning force microscopy (SFM) in combination with the use of diamond-tipped cantilevers can be used to scan or indent surfaces to explore the possibility of high-precision processing on such thin layers and to study mechanical processing characteristics $[12,18]$. Conductive atomic force microscopy (CAFM) can directly determine a local conductivity distribution using a boron-doped conductive diamond tip, which is independent of topographic information [19]. The local behavior of a conducting surface is investigated by measuring the electrical resistance between the surface and the tip. In the present study, lateral modulation friction force microscopy (LMFFM), as an application of an AFM, is used to measure the friction distribution in processed and unprocessed regions of multilayer films. Direct observations by LM-FFM can reveal the tribological characteristics of processed samples [20-22].

In this paper, we first report a method for evaluating the tribology of carbon nitride and boron nitride $(\mathrm{CN} / \mathrm{BN}) \mathrm{n}$ and $(\mathrm{BN} / \mathrm{CN}) \mathrm{n}$ nanoperiod multilayer films and their application to nanoscale processing. Nanoperiod multilayer $(\mathrm{CN} / \mathrm{BN}) \mathrm{n}$ and $(\mathrm{BN} / \mathrm{CN}) \mathrm{n}$ films with top $\mathrm{CN}$ and $\mathrm{BN}$ layers, respectively, were deposited by radio frequency (RF) sputtering. Their nanoindentation hardness, modulus of dissipation, and microwear resistance properties were evaluated. We attempted to process nanoscale profiles on nanoperiod multilayer films by applying the nanometer-scale wear mechanism of the films.

Second, we report on our investigation of the microprocessing characteristics of nanoperiod multilayer boron nitride and carbon $(\mathrm{C} / \mathrm{BN}) \mathrm{n}$ films employing an AFM and a boron-doped (B-doped) chemical vapor deposition (CVD) diamond-coated silicon tip by measuring the current in unprocessed and processed regions. Using a conductive diamond tip, nanoprocessing was carried out by sliding a sample coated with a $(\mathrm{C} / \mathrm{BN}) \mathrm{n}$ film under a load, and then the topography and electrical properties of the processed $(\mathrm{C} / \mathrm{BN}) \mathrm{n}$ film were observed using the same tip. The changes in contact resistance caused by sliding scans of the carbon (C) and the boron nitride (BN) layers were evaluated. The frictional properties in terms of the load applied to $(\mathrm{C} / \mathrm{BN}) \mathrm{n}$ films were studied, and the frictional properties of such films were quantitatively determined by measuring the amplitude phase of the surface profile, while applying a lateral vibration of $20 \mathrm{~nm}$ amplitude and $1 \mathrm{kHz}$ frequency during nanoprocessing.

\section{Experimental Methods}

2.1. Film Deposition Methods. Nanometer-period (CN/BN)n and $(\mathrm{BN} / \mathrm{CN}) \mathrm{n}$ multilayer films composed of alternate $\mathrm{CN}$ and $\mathrm{BN}$ layers were deposited using an RF sputtering apparatus, which can supply high-frequency power to both a target and substrate, as shown in Figure 1. Two semicircular targets of graphite (C) and hexagonal boron nitride (h$\mathrm{BN})$ were repeatedly set facing the specimen under $\mathrm{Ar}$ and $\mathrm{N}_{2}$ (5:1) atmospheres. An RF power of $13.56 \mathrm{MHz}$ was supplied to both the target and substrate holder. Before the deposition of the films, the substrate was pretreated by argon sputtering at $9.3 \mathrm{~Pa}$ plasma pressure and an RF power of $25 \mathrm{~W}\left(0.14 \mathrm{~W} \cdot \mathrm{cm}^{-2}\right)$ on the substrate side for $60 \mathrm{~min}$ to clean the work surface. Reactive sputtering was performed by supplying a $7 \mathrm{~Pa}$ plasma pressure. The RF powers on the sample side and target side were $100 \mathrm{~W}\left(0.57 \mathrm{~W} \cdot \mathrm{cm}^{-2}\right)$ and $300 \mathrm{~W}\left(1.7 \mathrm{~W} \cdot \mathrm{cm}^{-2}\right)$, respectively. Before deposition, sputter cleaning using Ar was performed as pretreatment $[4,14]$. 


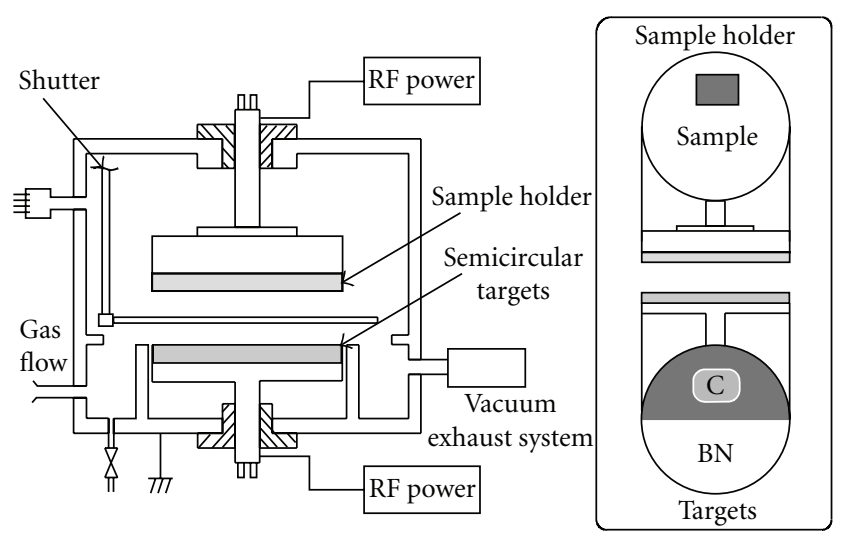

FIGURE 1: Schematic of RF sputtering.

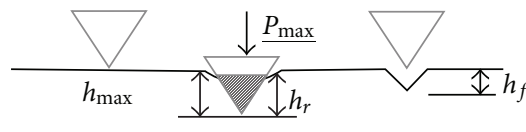

$P_{\max }$ : Maximum load

$h_{\text {max }}$ : Depth of plastic deformation

$h_{r}$ : End of indentation depth

$h_{f}:$ Final depth

$S_{1}$ : Dissipated energy

$S_{2}$ : Elastic energy

Modulus of dissipated $=$

$\frac{\text { Dissipated energy }}{\text { Dissipated energy }+ \text { elastic energy }} \times 100 \%$

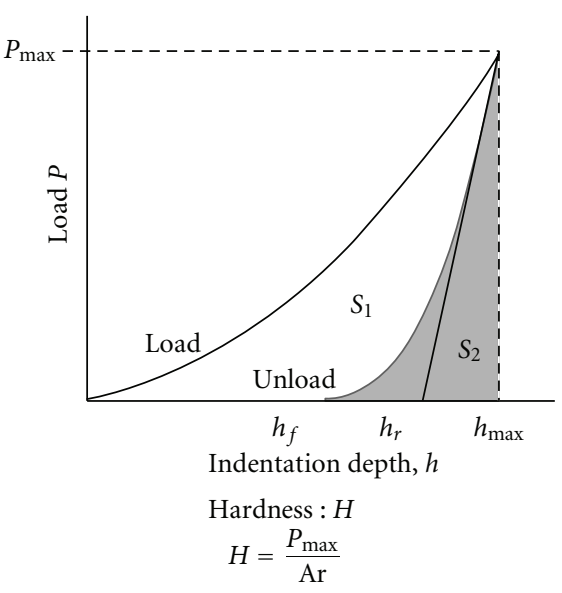

(a)

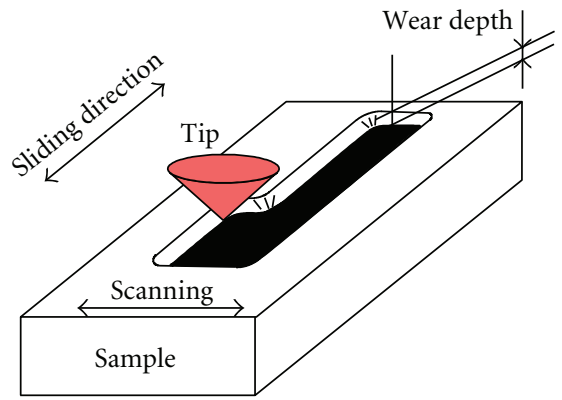

(b)

FIGURE 2: Evaluation methods in (a) nanoindentation test and (b) nanowear test.

In the deposition of 2-, 4-, 8-, and 10-nm-period $(\mathrm{CN} / \mathrm{BN}) \mathrm{n}$ multilayer films, in which the top layer was $\mathrm{CN}$, the substrate was first set opposite the h-BN target, and then rotated until it was opposite the $\mathrm{C}$ target. The total numbers of layers in the 2-, 4-, 8-, and 10-nm-period multilayer films were $200,100,50$, and 40 , respectively; therefore, the top surface was a CN layer. Nanometer-period (BN/CN)n multilayer films, in which the top layer was $\mathrm{BN}$ were deposited by a similar method. Under these conditions, a B-C-N mixed film was also deposited by setting the substrate at the midpoint between the two targets. The total thicknesses of the tested $(\mathrm{CN} / \mathrm{BN}) \mathrm{n}$ and $(\mathrm{BN} / \mathrm{CN}) \mathrm{n}$ films were approximately $200 \mathrm{~nm}$. The composition of the films was observed by transmission electron microscopy (TEM) [4].

$(\mathrm{BN} / \mathrm{C}) \mathrm{n}$ and $(\mathrm{C} / \mathrm{BN}) \mathrm{n}$ films were prepared by $\mathrm{RF}$ sputtering on $\mathrm{Si}(100)$ wafers in a vacuum chamber with a base pressure of 9.3 Pa. Alternate $\mathrm{C}$ and $\mathrm{BN}$ layers were, respectively, deposited on a silicon substrate with the $\mathrm{C}$ layer topmost by alternately rotating two semicircular targets of sintered $\mathrm{C}$ and $\mathrm{BN}$ to face the substrate in an atmosphere of argon $[4,13,23]$. The plasma-treated substrate was treated by supplying 9.3 Pa plasma pressure and RF powers of $25 \mathrm{~W}$ on the substrate side and $300 \mathrm{~W}$ on the target side. The thickness of each $\mathrm{BN}$ or $\mathrm{C}$ layer was determined by the time period for which the substrate was facing each target. 4-nm-period $(\mathrm{C} / \mathrm{BN}) \mathrm{n}$ and $(\mathrm{BN} / \mathrm{C}) \mathrm{n}$ multilayer films were deposited, as reported in our previous study [13]. The total thicknesses of these films were between 100 and $130 \mathrm{~nm}$.

2.2. Nanoindentation Hardness. To evaluate the hardness of the thin multilayer films, their nanoindentation behavior was also investigated as shown in Figure 2(a). A rectangular specimen was mounted on a plumbum zirconate titanate (PZT) plate, which could be moved to induce contact with an AFM tip and for loading and unloading. The nanoindentation deformation properties of the surfaces of the deposited films were investigated using an AFM (Digital Instruments Nanoscope III) together with a nanoindentation measurement system (Hysitron Inc.). The radius of the diamond tip used for indentation was approximately $100 \mathrm{~nm}$.

The hardness values of these films evaluated by this method under higher loads were lower than their actual hardness. These films were as thin as $200 \mathrm{~nm}$; therefore, the nanoindentation hardness values evaluated under higher loads were affected by the substrate hardness. The tests were performed with a loading time of $20 \mathrm{~s}$ at a load of 
$100-1000 \mu$ N. A Berkovich-type diamond indenter, that is, a triangular pyramid, was used. Here, the hardness was evaluated from the plastic deformation depth, which was evaluated from the point of intersection of the $y$-axis and the straight line fitting of the appropriate unloading curve [24]. In this study, the Vickers and nanoindentation hardness values of the silicon substrate were 1500 and $13 \mathrm{GPa}$, respectively.

To evaluate the deformation behavior observed in the nanoindentation test, energy analysis of the nanoindentation curve was performed. Total deformation energy was calculated as the integral of the loading curve as shown in Figure 2(a). Storage energy was calculated using the integral of the unloading curve. The dissipated energy was evaluated as the total energy minus the storage energy. The modulus of dissipation was calculated by dividing the dissipated energy by the total energy $[18,25]$.

2.3. Nanometer-Scale Wear Evaluation Using AFM. To evaluate the nanometer-scale wear properties of an extremely thin film, an AFM with an extremely sharp diamond tip (with a radius of nearly $50 \mathrm{~nm}$ ) was used as shown in Figure 2(b). The tip was supported by a parallel leaf-spring unit with a small spring constant. The diamond tip was slid against the specimen surface and the atomic interaction force between the specimen and tip was estimated from the tip displacement, which was measured using an optical head. Wear marks were formed by performing 1,5 , and 10 repeated scans with a $10 \mu \mathrm{N}$ load.

To clarify the reason for the increased hardness and wear resistance of nanoperiod multilayer films, the wear properties were investigated at a $4 \mu \mathrm{N}$ load, under which atomic-scale increases in wear depth were evaluated by varying the number of sliding cycles from 1 to 40 . The nanometer-scale wear depth was evaluated from the change in the surface profile measured using the same tip with a load of less than $160 \mathrm{nN}$ after the wear test. The wear profiles show the actual residual wear depth.

2.4. Nanoprocessing Method on Multilayer Film. On the basis of the nanometer-scale wear results, an AFM-based memory based on nanoprocessing by diamond-tip sliding was proposed, and grooves with one-layer depth were formed on the multilayer films. The basic nanoprocessing properties of these multilayer films were evaluated for their suitability as a high-density tribo-memory medium.

2.5. Micro-Electro-Mechanical Processing. To evaluate the nanoprocessing properties of a nanoperiod multilayer film, nanoprocessing was performed by the lateral vibration processing technique using an LM-FFM system, (Seiko Instruments Inc.) [26, 27]. In the LM-FFM system an AFM having a cantilever equipped with an extremely sharp electrically conductive diamond tip with a radius of approximately $45 \mathrm{~nm}$ was used to evaluate the surface profile and microprocessing properties. The spring constant of the cantilever (nanosensor; CDT-NCHR) was about $30 \mathrm{~N} / \mathrm{m}$.

Figure 3(a) shows a model of the processing method by LM-FFM. Processing tests were conducted by sliding the tip against a sample under a load with and without applying a lateral vibration of $10 \mathrm{~nm}$ amplitude and $1 \mathrm{kHz}$ frequency. As shown in Figure 3(b), during processing, an additional vibration, the direction of which was perpendicular to the scanning direction, was applied to the sample. This resulted in the torsional displacement of the cantilever of the tip due to the friction force between the tip and the sample. Figure 3(c) shows the trajectory of the AFM tip during processing. The amplitude of the torsional displacement of the cantilever was measured to determine the friction force between the sample and the tip. This amplitude (friction amplitude) is used later in this study to describe the friction force. The LM-FFM system was used to obtain a profile of the topography of the sample by scanning the tip over the sample surface. It was also used to probe the mechanical properties of the sample by measuring the amplitude and phase response of the sample at a small load of $100 \mathrm{nN}$ applied by the tip [21, 26-29].

Processing tests were conducted by tip sliding at loads of 500 and $4000 \mathrm{nN}$. The sample was moved in the $y$ direction with a speed of $3 \mu \mathrm{m} / \mathrm{s}$ while a vibration of $10 \mathrm{~nm}$ amplitude and $1 \mathrm{kHz}$ frequency was simultaneously applied in the $x$-direction (Figure $3(\mathrm{a})$ ). The processing area was $500 \times 500 \mathrm{~nm}^{2}$. The sample was then repeatedly scanned by the same tip at a load of $10 \mathrm{nN}$, a scanning speed of $1.5 \mu \mathrm{m} / \mathrm{s}$, and a scanning area of $1.5 \times 1.5$ or $3 \times 3 \mu \mathrm{m}^{2}$. The LM-FFM data consists of the output of 256 (pixels) $\times 256$ (lines) in the observation area and provides simultaneous measurement values of the surface topography and frictional force $[27,30]$. Nanoprocessing was performed with and without applying an additional lateral vibration to samples, respectively, with the aim of improving the processing efficiency and surface flatness.

In addition, the variation in the friction force in the processed area compared with that in the unprocessed area is defined as the ratio of the amplitude in the processed area (sliding area) to that in the unprocessed area. Processing tests were performed on three samples, and the variations in friction and processing depth were less than $10 \%$ under the $30-45 \%$ humidity.

\section{Tribological Characterization and Nanoprocessing of $(\mathrm{CN} / \mathrm{BN}) \mathrm{n}$ and (BN/CN)n Multilayer Films}

3.1. Composition and Structure of Deposited Films. The composition of the B-C-N films was evaluated by Auger electron spectroscopy (AES) analysis as shown in Figure 4(a) and all the depth profiles were evaluated under the same conditions so that the compositions of the films could be compared. The atomic ratios were estimated from the saturated values obtained from the depth profiles. The mean molecular percentages of carbon and nitrogen were nearly twice those of boron.

A schematic diagram and a TEM image of a nanometerperiod multilayer film composed of alternate C-N and B$\mathrm{N}$ layers are shown in Figures 4(b) and 4(c), respectively. The thicknesses of both the $\mathrm{C}-\mathrm{N}$ and $\mathrm{B}-\mathrm{N}$ layers were 


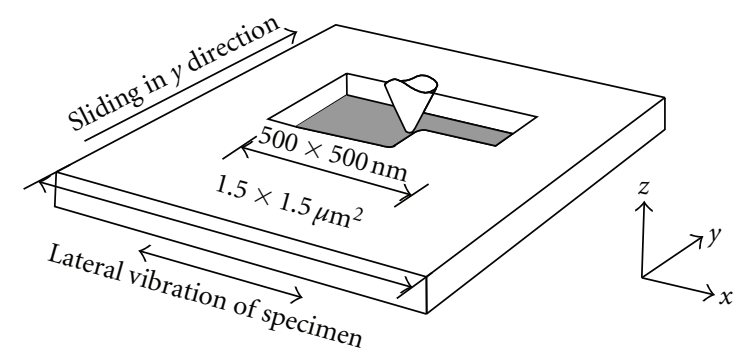

(a)

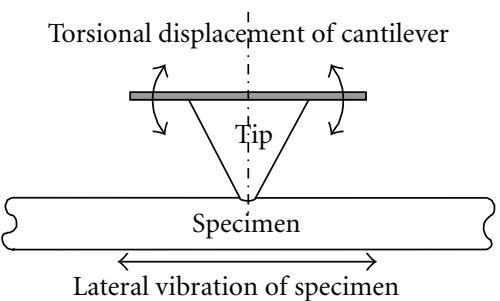

(b)

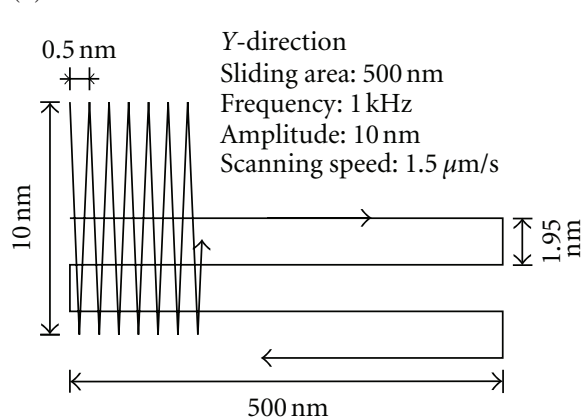

(c)

Figure 3: A model of the processing method by LM-FFM system (a), the torsional displacement of tip (b), and schematic of AFM tip trajectory during processing $(\mathrm{c})$.

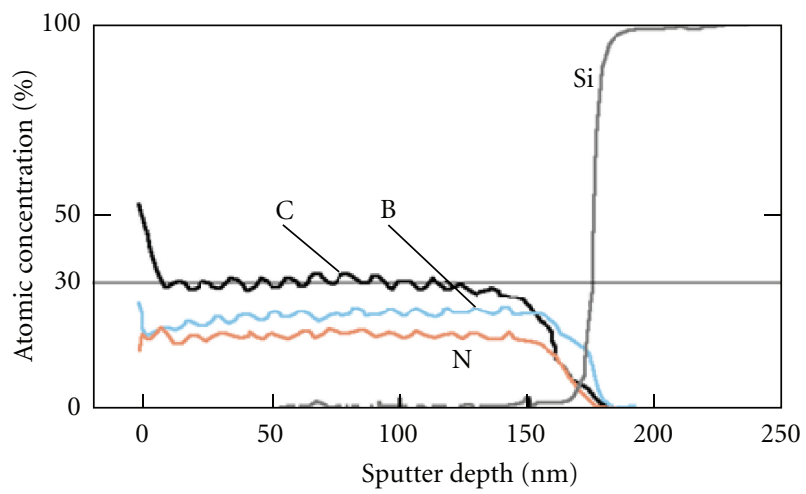

(a) AES depth profile of multilayer film

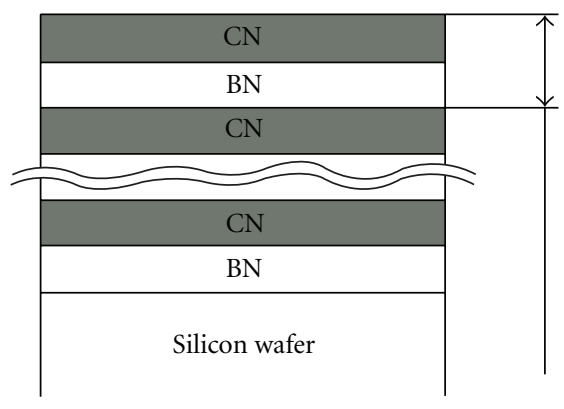

(b) Structure model

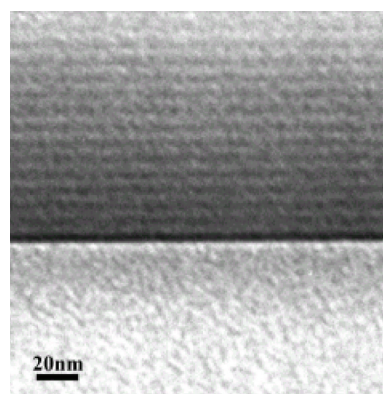

(c) TEM image

FIGURE 4: AES depth profile of multilayer film (a), model of multilayer film (b), and TEM image of nanoperiod multilayer film with a period of $8 \mathrm{~nm}$ (c). 


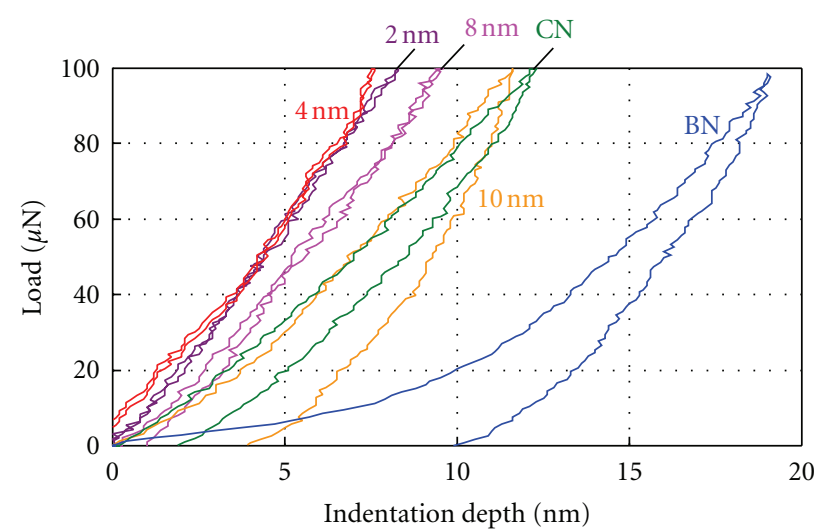

(a)

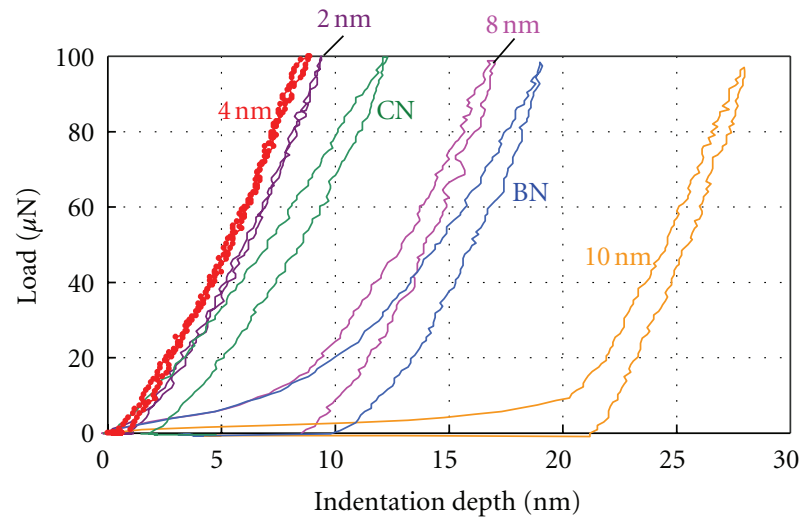

(b)

FIGURE 5: Nanoindentation curves of (a) (CN/BN)n and (b) (BN/CN)n films.

controlled so as to be nearly identical. The period of the multilayer film in the TEM image is $8 \mathrm{~nm}$; therefore, the thickness of each C-N of B-N layer is about $4 \mathrm{~nm}$. Even though the layers are very thin, each layer can be distinguished. However, the interface between the $\mathrm{C}-\mathrm{N}$ and $\mathrm{B}-\mathrm{N}$ layers is not clear. These $\mathrm{C}-\mathrm{N}$ and $\mathrm{B}-\mathrm{N}$ layers overlapped with each other at their interface.

3.2. Nanoindentation Properties. The indentation curves of the $(\mathrm{CN} / \mathrm{BN}) \mathrm{n}$ films, in which the top layer is $\mathrm{CN}$, and those of the $(\mathrm{BN} / \mathrm{CN}) \mathrm{n}$ films, in which the top layer is $\mathrm{BN}$, were obtained at a maximum applied load of $100 \mu \mathrm{N}$ and are shown in Figures 5(a) and 5(b), respectively. The $(\mathrm{CN} / \mathrm{BN}) \mathrm{n}$ and (BN/CN)n multilayer films with 2 and $4 \mathrm{~nm}$ periods exhibit nearly elastic properties, and the residual depth $h f$ is nearly zero. A (CN/BN)n multilayer film with $10 \mathrm{~nm}$ period exhibits elastic-plastic properties.

The maximum deformation depths of the $(\mathrm{BN} / \mathrm{CN}) \mathrm{n}$ films are markedly larger than those of the $(\mathrm{CN} / \mathrm{BN}) \mathrm{n}$ films with 8 and $10 \mathrm{~nm}$ periods. The deformation properties of the 8- and 10-nm-period (BN/CN)n films resemble those of the BN films, and deformation depth rapidly increases with load. A markedly larger deformation depth is observed in the case of the $10 \mathrm{~nm}$ period; therefore, defects are easily generated and elongate on the BN top layer. Compared with $\mathrm{CN}$ and $\mathrm{BN}$ single-layer films, the hardness of the $\mathrm{BN}$ layer is markedly low; therefore, the defects on the $\mathrm{BN}$ layer are easily enhanced and increased. A weak BN top layer is easily deformed permanently by mechanical action.

Therefore, there is a large difference between the permanent deformation resistances of the $(\mathrm{CN} / \mathrm{BN}) \mathrm{n}$ and (BN/CN)n films. The plastic deformation of the BN top layer rapidly increases with increasing load even at a low load. The mechanical properties of the multilayer films are strongly affected by the properties of the top layer.

The dissipated and storage energies after the indentation of the multilayer films are shown in Figure 6. The dissipated energies of the 2-, 4-, and 8-nm-period ( $\mathrm{CN} / \mathrm{BN}) \mathrm{n}$ films, in which $\mathrm{CN}$ is the top layer, are markedly small. These results suggest that the amount of permanent deformation

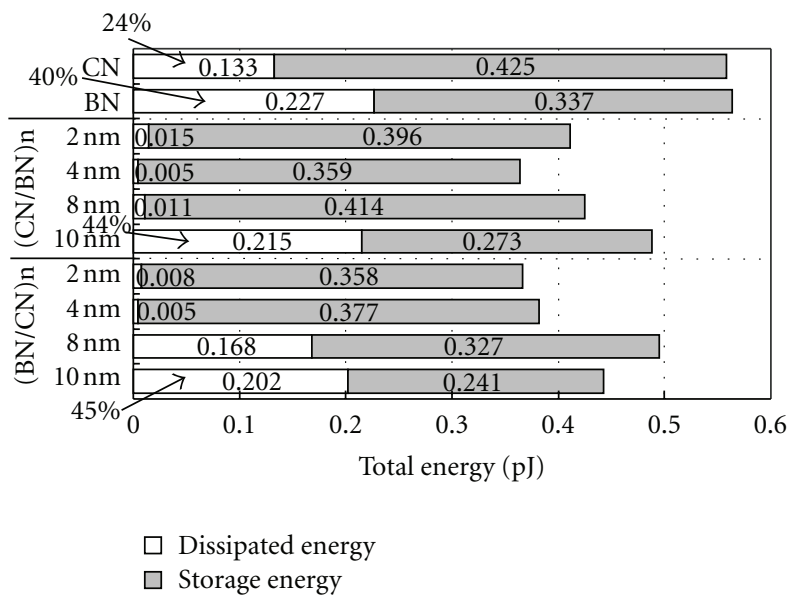

Figure 6: Dissipated and storage energies of $(\mathrm{CN} / \mathrm{BN}) \mathrm{n}$ and $(\mathrm{BN} / \mathrm{CN}) \mathrm{n}$ films, measured by nanoindentation test.

such as plastic deformation decreases, and that the load was mainly supported by elastic deformation. In contrast, the dissipated energies of the $\mathrm{BN}$ and 10-nm-period $(\mathrm{CN} / \mathrm{BN}) \mathrm{n}$ and 8 - and $10-\mathrm{nm}$-period $(\mathrm{BN} / \mathrm{CN}) \mathrm{n}$ multilayer films are very large; therefore, permanent deformations such as the plastic deformation and brittle fracture of these films are easily produced by nanoindentation.

The hardness and modulus of dissipation of the $(\mathrm{CN} / \mathrm{BN}) \mathrm{n}$ multilayer films change with the layer period, as shown in Figure 7(a). The hardnesses of the multilayer films are higher than those of $\mathrm{BN}$ and $\mathrm{CN}$ single-layer films. The hardnesses of the $(\mathrm{BN} / \mathrm{CN}) \mathrm{n}$ films are similar to those of the $(\mathrm{CN} / \mathrm{BN}) \mathrm{n}$ films as shown in Figure $7(\mathrm{~b})$; however, the hardnesses of the 8- and 10-nm-period (BN/CN)n multilayer films are as low as that of the BN film. This shows that the top $\mathrm{BN}$ layer of the multilayer film is easily fractured.

The reason why the hardness of the $10 \mathrm{~nm} \mathrm{BN}$ top layer on the BN/CN multilayer film is lower than that of the pure $\mathrm{BN}$ film is not clear, although the data was found to be repeatable and reliable. The $(\mathrm{BN} / \mathrm{CN}) \mathrm{n}$ film is not soft 


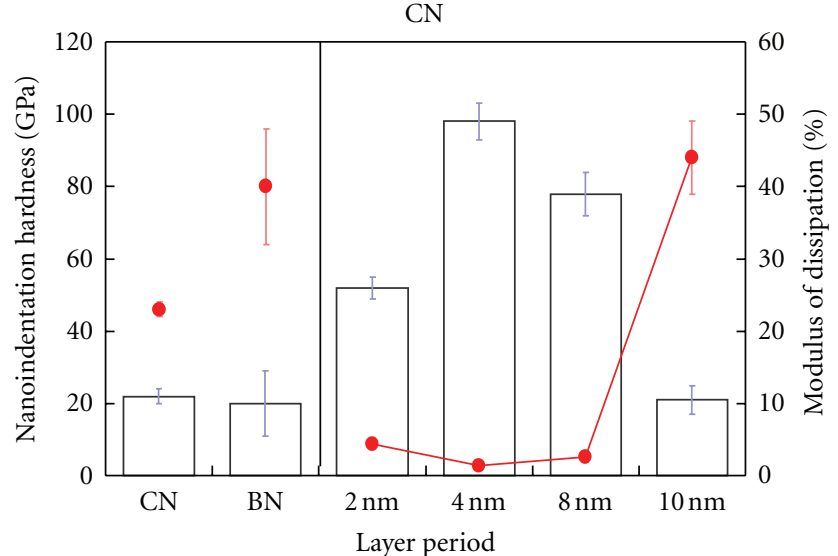

Hardness

Modulus of dissipation

(a)

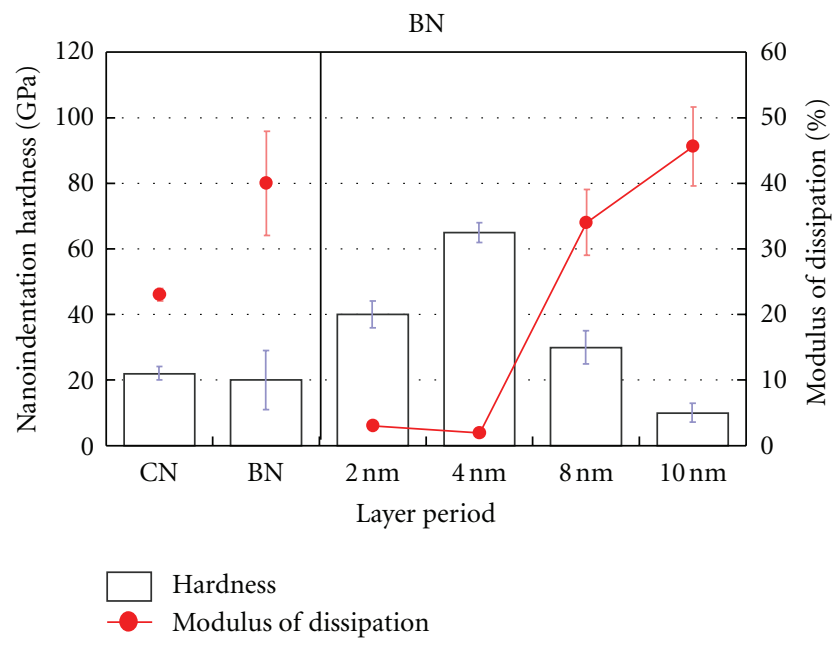

(b)

FIGURE 7: Nanoindentation hardness and modulus of dissipation of (a) $(\mathrm{CN} / \mathrm{BN}) \mathrm{n}$ and $(\mathrm{b})(\mathrm{BN} / \mathrm{CN}) \mathrm{n}$ films.

because its nanoscale wear resistance is similar to that of a $\mathrm{BN}$ single-layer film. Therefore, from the shape of the indented top BN layer of approximately $10 \mathrm{~nm}$ thickness, it is surmised that the indenter glides deep into the surface without encountering a large resistance. Because the thickness of the top $\mathrm{BN}$ layer is only $10 \mathrm{~nm}$, the following $\mathrm{CN}$ layer cannot stop or reduce the penetration which accelerates when the indentation depth reaches $10 \mathrm{~nm}$.

The relationship between the modulus of dissipation and nanoindentation hardness is shown in Figure 8. The dependence of the modulus of dissipation on the nanoindentation hardness for the $(\mathrm{CN} / \mathrm{BN}) \mathrm{n}$ films is similar to that for the $(\mathrm{BN} / \mathrm{CN}) \mathrm{n}$ films. The modulus of dissipation decreases as the nanoindentation hardness increases. The modulus of dissipation of the hardest 4-nm-period multilayer film is the smallest, and deformation mainly involves elastic deformation with minimal dissipated energy.

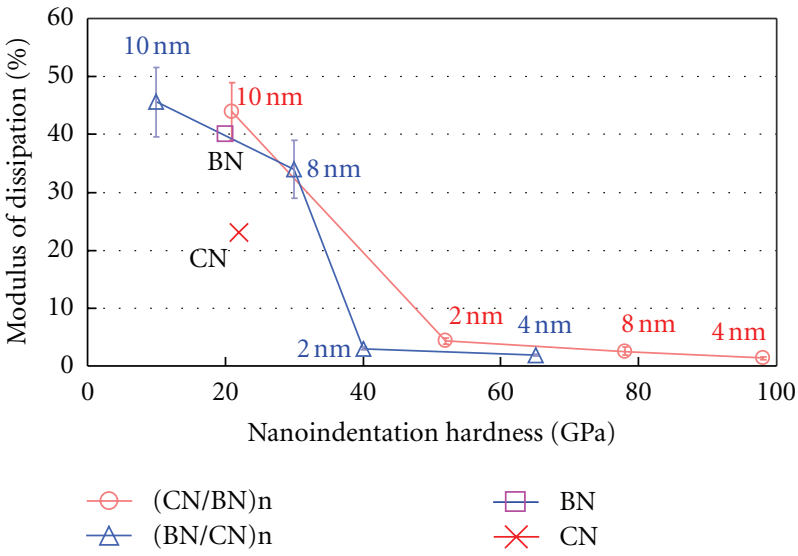

FIgURE 8: Relationship between nanoindentation hardness and modulus of dissipation of multilayer films.

3.3. Nanometer-Scale Wear Testes. The dependence of the nanometer-scale wear profile on the layer period of the multilayer films at $10 \mu \mathrm{N}$ load is shown in Figure 9. The nanometer-scale wear depth of the multilayer film changes with the layer period. The wear depth of the 2-nm-period film is nearly $1 \mathrm{~nm}$, and the wear depth of the $4-\mathrm{nm}$ period film is less than that of the 2-nm-period film. For periods exceeding $4 \mathrm{~nm}$, the wear depth increases with the layer period. Nanometer-scale wear profiles obtained under the same conditions are considerably different between the $(\mathrm{CN} / \mathrm{BN}) \mathrm{n}$ and $(\mathrm{BN} / \mathrm{CN}) \mathrm{n}$ multilayer films as shown in Figure 10 . Wear marks on the $(\mathrm{CN} / \mathrm{BN}) \mathrm{n}$ film were hardly observed, although the tip slid at the center. In contrast, a large wear scar was observed on the $(\mathrm{BN} / \mathrm{CN}) \mathrm{n}$ films. Defects are easily formed the (BN/CN)n films with the top $\mathrm{BN}$ layer which are caused by tip sliding as observed in the nanoindentation testes. These results show that a suitable top layer is important for realizing increased hardness and superior wear resistance.

Figure 11 shows the dependence of the nanometer-scale wear properties of the $(\mathrm{CN} / \mathrm{BN}) n$ and $(\mathrm{BN} / \mathrm{CN}) \mathrm{n}$ films on the layer period. For the $(\mathrm{BN} / \mathrm{CN}) \mathrm{n}$ films the smallest wear depth is obtained at a $4 \mathrm{~nm}$ period, similarly to the $(\mathrm{CN} / \mathrm{BN}) \mathrm{n}$ films. However, the wear depths of $(\mathrm{BN} / \mathrm{CN}) \mathrm{n}$ films are greater than those of the $(\mathrm{CN} / \mathrm{BN}) \mathrm{n}$ films at every layer period. The wear depth of the B-C-N film was greater than those of both the 4- and 8-nm-period (CN/BN)n multilayer films. The wear depth of the 4-nm-period (CN/BN)n multilayer film is the smallest for all numbers of sliding cycles; therefore, the wear resistance is clearly greater in the $4-\mathrm{nm}$-period $(\mathrm{CN} / \mathrm{BN}) \mathrm{n}$ multilayer film.

The wear resistance exhibited a tendency similar to that of nanoindentation hardness. The wear depths of the $(\mathrm{CN} / \mathrm{BN}) \mathrm{n}$ multilayer films with 4 and $8 \mathrm{~nm}$ periods are small, which indicates that the nanometer scale wear resistance is clearly improved when a multilayer structure with an appropriate layer period and top surface is deposited, similarly to in the nanoindentation results.

To clarify the atomic-scale wear properties, wear tests using an AFM were performed at a $4 \mu \mathrm{N}$ load, for which the wear increases at the atomic scale. The dependence of 


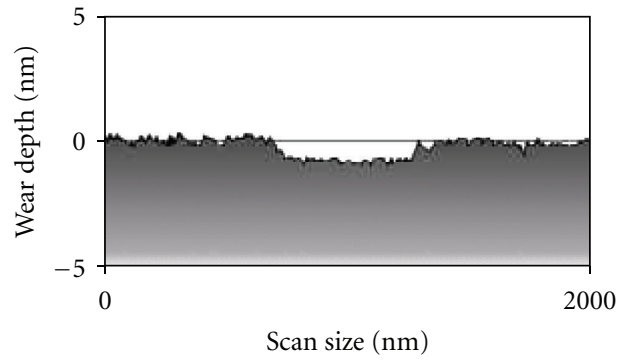

(a) layer period $2 \mathrm{~nm}$

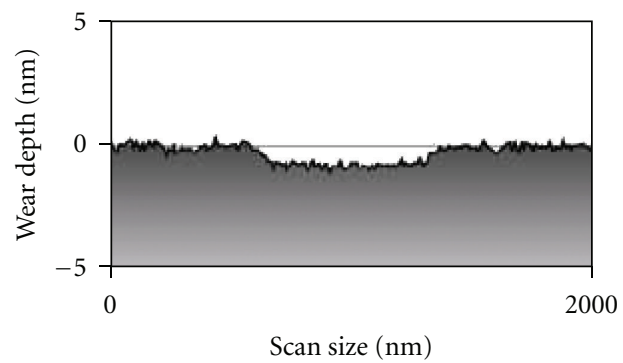

(c) Layer period $8 \mathrm{~nm}$

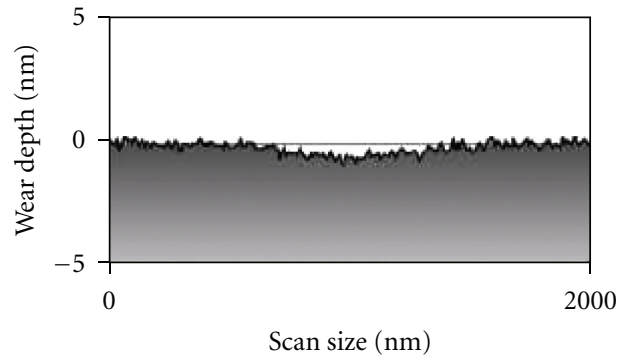

(b) layer period $4 \mathrm{~nm}$

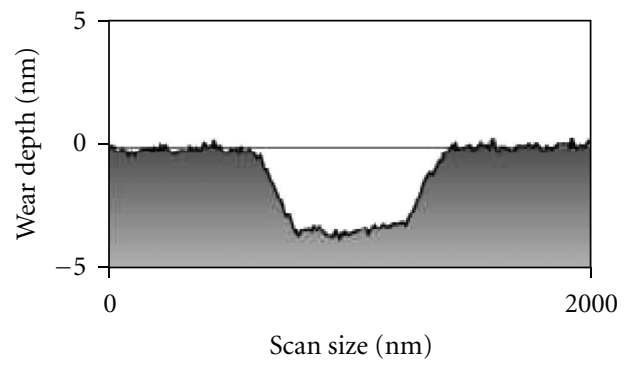

(d) Layer period $10 \mathrm{~nm}$

Figure 9: Dependence of nanometer-scale wear properties on layer period of (CN/BN)n multilayer films obtained by applying a load of $10 \mu \mathrm{N}$ and one number of scanning cycle.

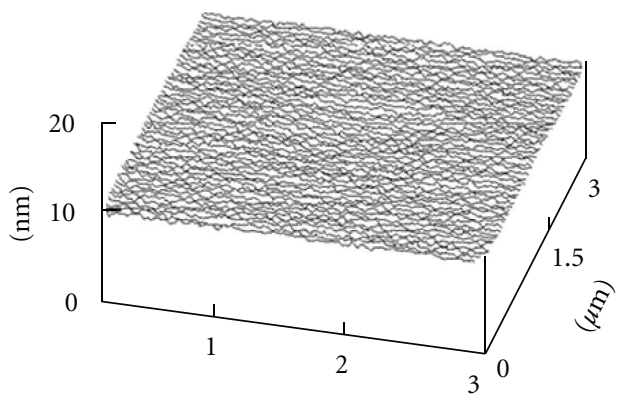

(a) $(\mathrm{CN} / \mathrm{BN}) \mathrm{n}$

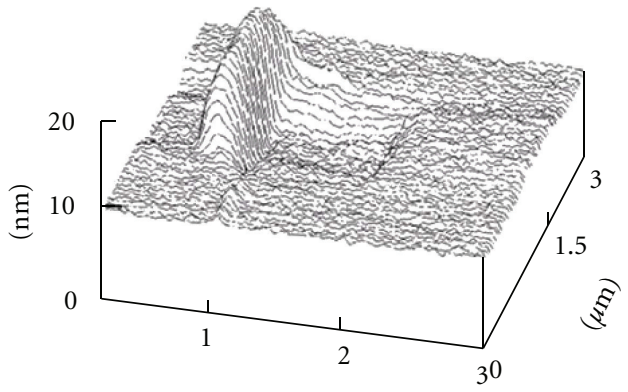

(b) $(\mathrm{BN} / \mathrm{CN}) \mathrm{n}$

Figure 10: Nanowear of (a) (CN/BN)n and (b) (BN/CN)n films with a layer period of $4 \mathrm{~nm}$, obtained by applying a load of $50 \mu \mathrm{N}$ and one number of scanning cycle.

wear depth on the number of sliding cycles is shown in Figure 12. In the figure, 1st and 2nd refer to the results of two separate tests performed on two different $(\mathrm{CN} / \mathrm{BN}) \mathrm{n}$ samples prepared under the same deposition conditions. The rate of increase in the wear for the 4-nm-period multilayer film is almost zero at depths of $2,4,6$, and $8 \mathrm{~nm}$, as shown in Figure 12(a). These $2 \mathrm{~nm}$ intervals correspond to the thickness of each $\mathrm{CN}$ and $\mathrm{BN}$ layer in the 4-nm-period multilayer film. This result shows that the wear rate decreases at the interface between layers.

The rate of increase in the wear for the 2-nm-period multilayer film is also nearly zero at depths of $1,2,3$, and $4 \mathrm{~nm}$, as shown in Figure 12(b). Similarly, that for the 8-nmperiod film is nearly zero at depths of 4 and $8 \mathrm{~nm}$ as shown in Figure 12(c). These wear depths correspond to multiples of the $\mathrm{CN}$ and $\mathrm{BN}$ layer thickness in each multilayer film. These results show that the wear resistance increases at the interfaces between the $\mathrm{CN}$ and $\mathrm{BN}$ layers. The increase in the wear resistance and hardness of the $(\mathrm{CN} / \mathrm{BN}) \mathrm{n}$ multilayer films is due to the existence of the interfaces, which prevent the elongation of defects which leads to the occurrence of dislocations and cracks $[4,14,31]$.

The nanoscale structural differences between the interface and the inner layer cannot be observed by microanalysis, but the structure of the B-C-N interfaces is similar to that of mixed $\mathrm{B}-\mathrm{C}-\mathrm{N}$ because the same deposition conditions were used. However, the multilayer films exhibit superior wear resistance to the pure B-C-N film. The superior hardness and wear resistance of the multilayer films confirm that the interface prevents defect elongation along preferential structure directions owing to the change in the nanoscale structure between different material layers. In the defect elongation of nanoperiod multilayer films composed of crystalline materials, cracks propagate along preferential crystalline directions and are stopped when the crystalline structure is disturbed by layer interfaces. The multilayer films were found to be amorphous by microanalysis; however, 


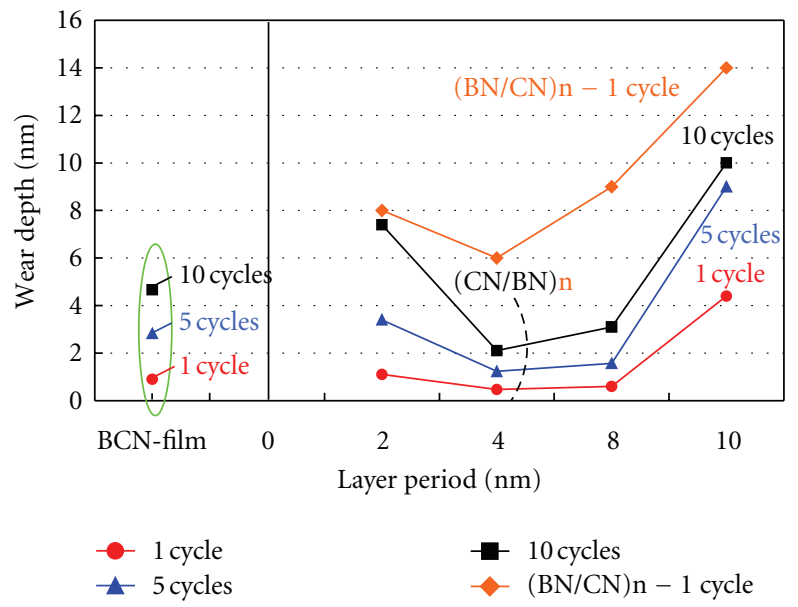

FIGURE 11: Dependence of nanowear on layer period of multilayer films obtained at a load of $10 \mu \mathrm{N}$ from 1 to 10 scanning cycles.

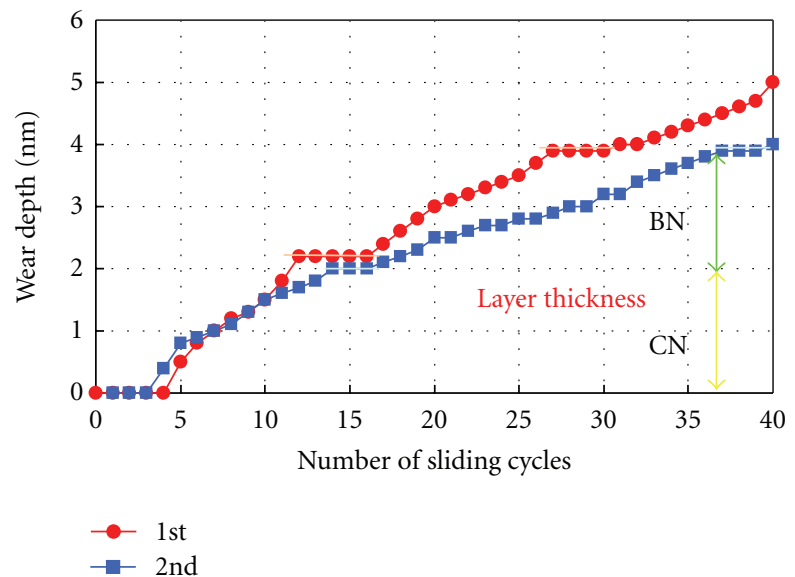

(a)
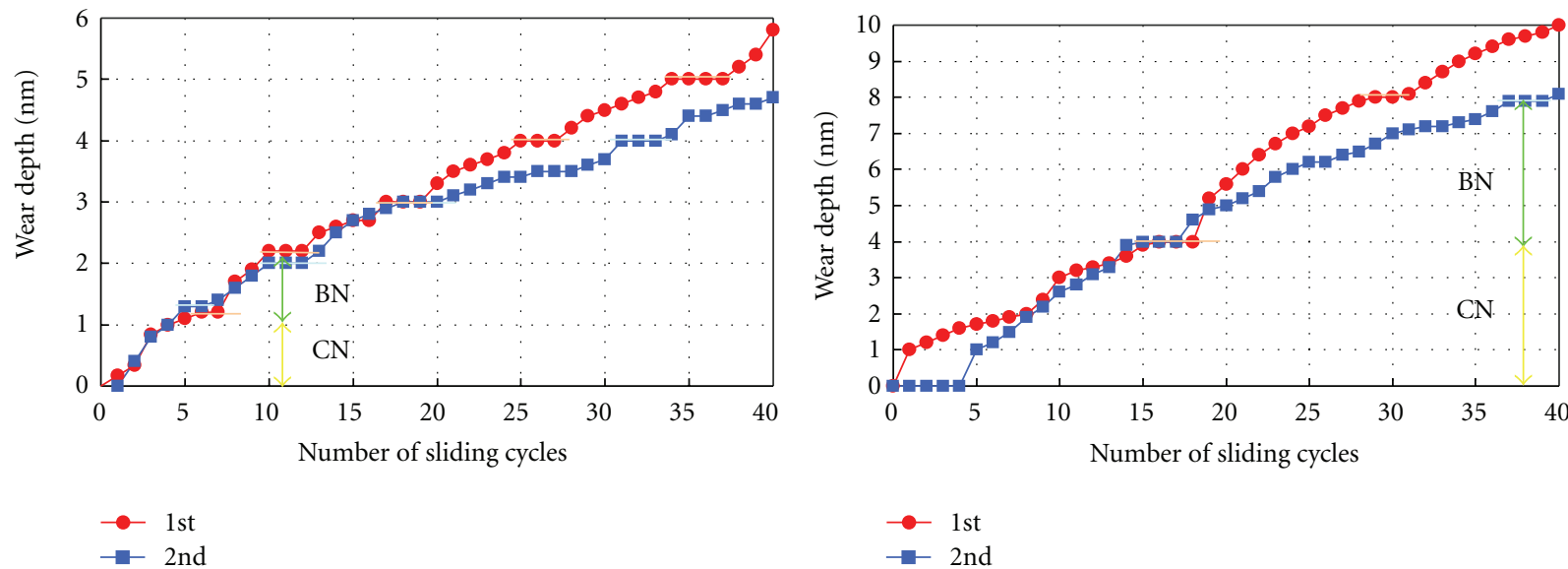

(b)

(c)

Figure 12: Nanowear depth dependence on number of scanning cycles for (a) 4-nm-period, (b) 2-nm-period, and (c) 8-nm-period multilayer films. 
the layers have different compositions and structures on the nanoscale, therefore, the interfaces prevent defect elongation similarly to in a crystalline material, as shown in Figure 12.

The hardness and wear resistance of the 4-nm-period multilayer films are higher than those of the 2-nm-period multilayer films, even though the latter have more interfaces within the same thickness than the former. Similar results were obtained for the $(\mathrm{BN} / \mathrm{CN}) \mathrm{n}$ film. By the rotating of the specimen during deposition, interface layers with a thickness of $0.6 \mathrm{~nm}$ were formed. The 1-nm-thick CN and BN layers in the 2-nm-period multilayer film could not be clearly observed as separate layers. These films have the same interface but the ratio of the thickness of the interface to that of each layer is different. Therefore, the preventability of defect elongation in terms of the mean number of sliding cycles during which wear did not increase at the interface was investigated [4]. The mean number of sliding cycles of the 4-nm-period multilayer film is nearly twofold that of the 2-nm-period multilayer film. Therefore, the ability of the interfaces of the 2-nm-period film to prevent defect elongation is lower than that of the 4-nm-period film, and the microwear resistance of the former is similar to that of the B-C-N single-layer films as shown in Figure 11. These results suggest that the mechanical processing of atomic-scale grooves in a layered film can be achieved using this layer-bylayer nanometer-scale wear mechanism.

3.4. Nanoprocessing of Multilayer Films by Applying Nanometer-Scale Wear Mechanism. By using the phenomena in which the increase in nanometer scale wear was prevented at the interface, we attempted nanometer-scale layer-by-layer processing of multilayer films by diamond tip sliding using an AFM. Because it is difficult to control the processing depth of $(\mathrm{BN} / \mathrm{CN}) \mathrm{n}$ films owing to the lower strength of their top $\mathrm{BN}$ layer, $(\mathrm{CN} / \mathrm{BN}) \mathrm{n}$ films were processed layer by layer.

3.4.1. Nanoprocessing of One-Layer-Deep Grooves. The nanoprocessing of 2-nm-deep grooves on a 4-nm-period $(\mathrm{CN} / \mathrm{BN}) \mathrm{n}$ film, where the depth of the grooves corresponds to the thickness of the layer immediately underneath it, was attempted by diamond tip sliding. Figure 13(a) shows lines of $1000 \mathrm{~nm}$ length processed at a load of approximately $30 \mu \mathrm{N}$. This profile of the grooves is inverted to clearly show the bottoms of the grooves. Processed grooves with a width of nearly $70 \mathrm{~nm}$ were formed. A cross-sectional profile of the processed line grooves is shown in Figure 13(b). The depths of all processed grooves are nearly $2.0 \mathrm{~nm}$, corresponding to the thickness of one $\mathrm{CN}$ layer. Thus, under suitable conditions, the mechanical sliding of the tip generated 2-nm-deep grooves, which corresponds to the depth from the top surface of $\mathrm{CN}$ to the next $\mathrm{BN}$ layer underneath it.

3.4.2. Processing of Three-Step Grooves. Three-step grooves processed on 4- and 2-nm-period (CN/BN)n multilayer films are shown in Figures 14(a) and 14(b), respectively. Three rectangular grooves were processed by diamond tip sliding. The scanning area was $400 \times 400 \mathrm{~nm}^{2}$. The three grooves were processed by applying loads of 40,50, and $70 \mu \mathrm{N}$. The profiles are inverted to clearly show the bottoms of the grooves, which are atomically smooth. According to the cross-sectional profiles of the grooves, the depths of the grooves processed at loads of 40,50 , and $70 \mu \mathrm{N}$ are 2, 4, and $6 \mathrm{~nm}$, respectively. These results show that the processed depth in each rectangular area was nearly a multiple of $2 \mathrm{~nm}$ corresponding to the layer thickness. The processed three-step groove on the 2-nm-period $(\mathrm{CN} / \mathrm{BN}) \mathrm{n}$ film is shown in Figure 14(b). One-nm-thick $\mathrm{CN}$ and $\mathrm{BN}$ layers were laminated, and the removal of material could easily be stopped at the interfaces between the $\mathrm{CN}$ and $\mathrm{BN}$ layers of the 2-nm-period (CN/BN)n film. Grooves were experimentally processed with 1 and $2 \mathrm{~nm}$ depths. A three-step groove was successfully processed layer-by-layer on the 2-nm-period multilayer film, where the groove depths were multiples of $1 \mathrm{~nm}$.

\section{Nanoprocessing and Characterization of (BN/C)n and (C/BN)n Films}

4.1. Nanoprocessing and Characterization of (BN/C)n Film. A 4-nm-period (BN/C)n film was processed by sliding using an AFM tip with a radius of nearly $50 \mathrm{~nm}$ at a load of $1000 \mathrm{nN}$ while applying a lateral vibration of $20 \mathrm{~nm}$ amplitude and $1 \mathrm{kHz}$ frequency. The wear area was $0.5 \times 0.5 \mu \mathrm{m}^{2}$. The test was performed in air at about 50\% humidity. The normal force used for imaging was $10 \mathrm{nN}$. The mean wear depth was obtained by scanning five different areas on the sample surface. In addition, hardly any wear debris was observed at the periphery of the wear area and at the tip. Furthermore, the diamond tip was observed before and after processing and hardly any change in the tip radius was observed [32]. It is considered that the wear debris is removed by tip sliding during processing.

Figure 15 shows a schematic diagram of the layers and thickness of 4-nm-period multilayer (BN/C)n and (C/BN)n films. To discuss the microstructure of the (BN/C)n multilayer films, information about the processing properties is necessary. The topographic, current, and friction images obtained after attempting to process a $4-\mathrm{nm}$-period (BN/C)n film at a load of $1000 \mathrm{nN}$ are shown in Figures 16-18, respectively [33]. As shown in Figure 16, the wear groove is about $2.5 \mathrm{~nm}$ deep. This indicates that the topmost $\mathrm{BN}$ layer was removed first, and then the wear track reached the next layer, that is, the $C$ layer, upon loading. In the current image (Figure 17), the bright regions represent a high flowing current. That is, the corresponding area shows that the current flowing in the scanned area was significantly higher than that in the unprocessed area. Moreover, the current flowing inside the scanned area is markedly higher than that at the periphery of the scanned area (Figure 17(b)). The current generally increased as the tip was scanned from the $\mathrm{BN}$ layer to the $\mathrm{C}$ layer. This suggests that the conductivity of the $\mathrm{C}$ layer is higher than that of the $\mathrm{BN}$ layer, possibly due to the graphite phase having high conductivity. The image in Figure 18(a) showing the friction distribution suggests that, compared with the unprocessed area, the frictional 


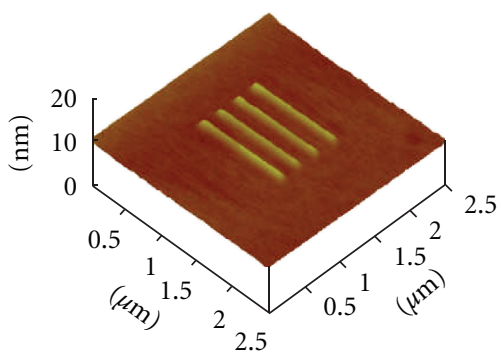

(a) Inverted image

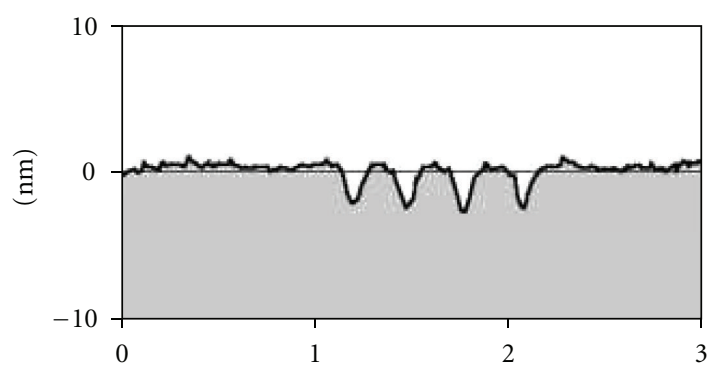

(b) Section profile

FIGURE 13: Processed line and space pattern with a pitch of $200 \mathrm{~nm}$ on 4-nm-period (CN/BN)n multilayer film obtained at a load of $30 \mu \mathrm{N}$.

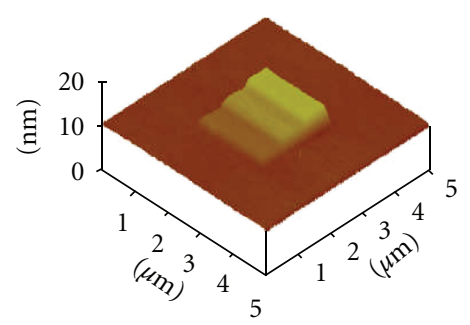

(a) Inverted image

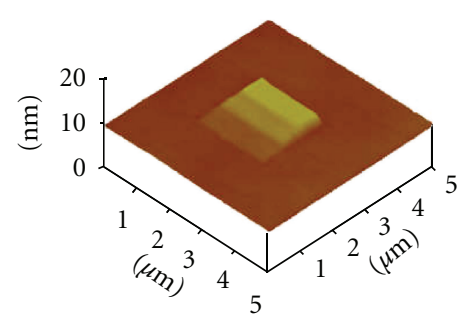

(a) Inverted image

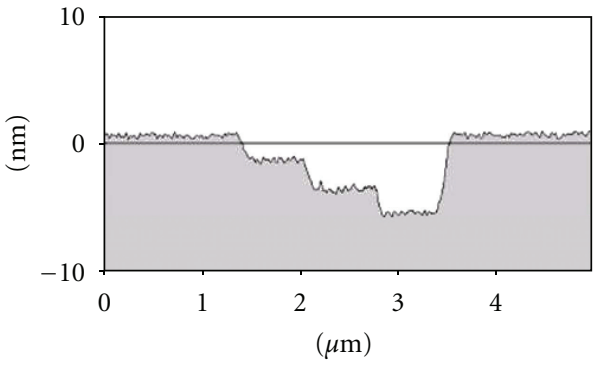

(b) Section profile

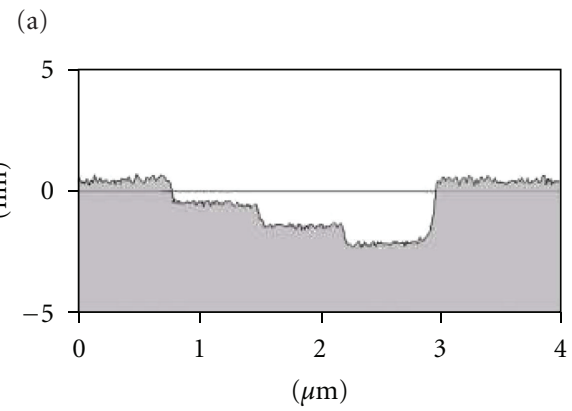

(b) Section profile

(b)

Figure 14: Three-step grooves on the nanoperiod multilayer films. (a) CN/BN 4-nm-period film; processing loads of 40, 50, 70 $\mu$ N from left to right. (b) CN/BN 2-nm-period film; processing loads of $10,15,20 \mu \mathrm{N}$ from left to right.

force at the center of the scanned area was lower, whereas it was larger at the periphery of the scanned area. As shown in Figure 18(b), when the conductive tip scanned the peripheral region where the $\mathrm{BN}$ layer exists, the contact friction increased, whereas when the tip scanned the center of the wear groove under loading, the wear reached the $\mathrm{C}$ layer, resulting in a decrease in the frictional force.

4.2. Nanoprocessing and Characterization of $(C / B N) n$ Film. Using the LM-FFM system, a 4-nm-period (C/BN)n film was processed by sliding a tip at a load of $3500 \mathrm{nN}$, while applying a lateral vibration of $20 \mathrm{~nm}$ amplitude and $1 \mathrm{kHz}$ frequency. A sharp tip with a radius of about $30 \mathrm{~nm}$ was used in this process. To evaluate the variation in the current and frictional force of the 4-nm-period $(\mathrm{C} / \mathrm{BN}) \mathrm{n}$ film, we investigated the current and frictional force at the same wear depth as that of the 4-nm-period (BN/C)n film. Figures 19-21, respectively, show the topographic, current, and friction images of a wear mark made in the $4-\mathrm{nm}$ period $(\mathrm{C} / \mathrm{BN}) \mathrm{n}$ film at a load of $3500 \mathrm{nN}$. The mean wear depth was obtained by scanning five different areas on the sample surface. As shown in Figure 19, the mean wear depth was about $2.5 \mathrm{~nm}$ at the load of $3500 \mathrm{nN}$, that is, the topmost $\mathrm{C}$ layer was removed and the wear track reached the $\mathrm{BN}$ layer. It is clear that the $\mathrm{C}$ layer is harder than the $\mathrm{BN}$ layer. Figure 20 shows the current distribution profile and a cross-sectional image of the film. According to the figure, the current flowing inside the scanned area was lower than that at its periphery; a brighter area corresponds to a higher electrical current flowing. This result is due to the different electrical conductivities of each layer, that is, the electrical current increased when the conductive tip came in contact 


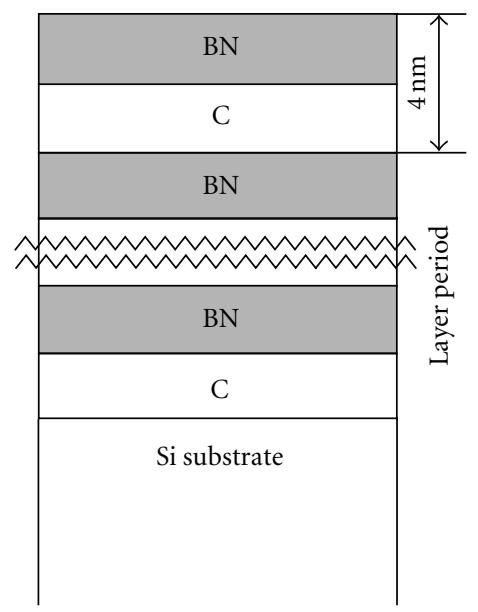

(a) $(\mathrm{BN} / \mathrm{C}) \mathrm{n}$

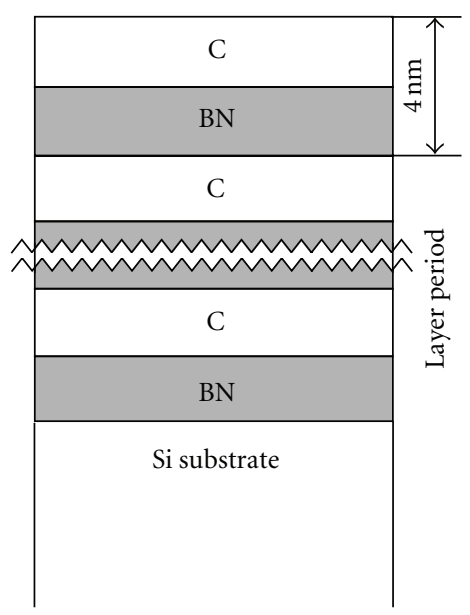

(b) $(\mathrm{C} / \mathrm{BN}) \mathrm{n}$

FIGURE 15: Schematic of layers and thickness of 4-nm-period multilayer (a) (BN/C)n and (b) (C/BN)n films.
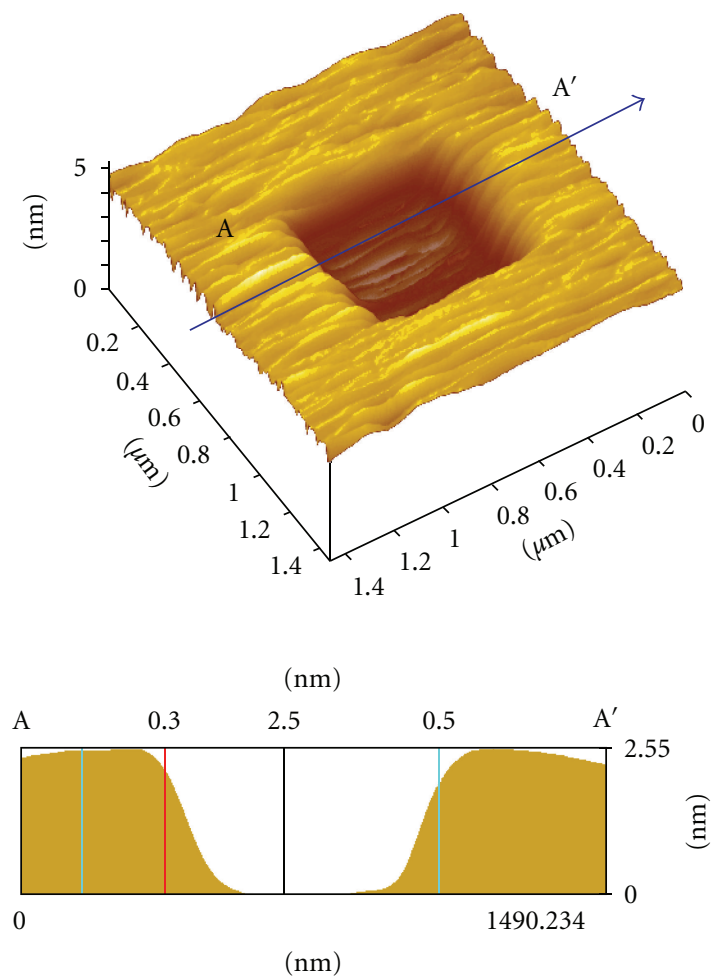

Figure 16: Profile and cross-sectional images of 4-nm-period (BN/C)n topography at $1000 \mathrm{nN}$ load and vibration amplitude of $20 \mathrm{~nm}$.

with the $\mathrm{C}$ layer, whereas it decreased when it came in contact with the BN layer. On the other hand, in the friction distribution image (Figure 21), the contact friction in the scanned area is higher than that in the unprocessed area. Figure 21(b) shows that the conductive tip came in contact with the $\mathrm{C}$ layer at the periphery of the scanned area and then reached the BN layer upon loading. This shows that the contact frictional force at the $\mathrm{C}$ layer is lower than that at the BN layer. On the other hand, since the wear depth was about $2.5 \mathrm{~nm}$, the wear track is considered to be a mixed layer composed of $\mathrm{C}$ and $\mathrm{BN}$ phases. Therefore, it is considered that this mixed layer may have been formed between the $\mathrm{C}$ layer and the $\mathrm{BN}$ layer owing to the alternating target consisting of sintered graphite and boron nitride and that it is an interface with high frictional force and high conductive resistance. These results indicate that the contact friction increased as the tip came in contact with the interface as well as with the $\mathrm{BN}$ layer. Corresponding to this, the conductive resistance at the contact between the tip and the $\mathrm{BN}$ layer as well as with the interface increased during scanning, resulting in a decrease in current flow. Since the current is higher at the periphery of the groove than that at its center (Figure 21(b)), 

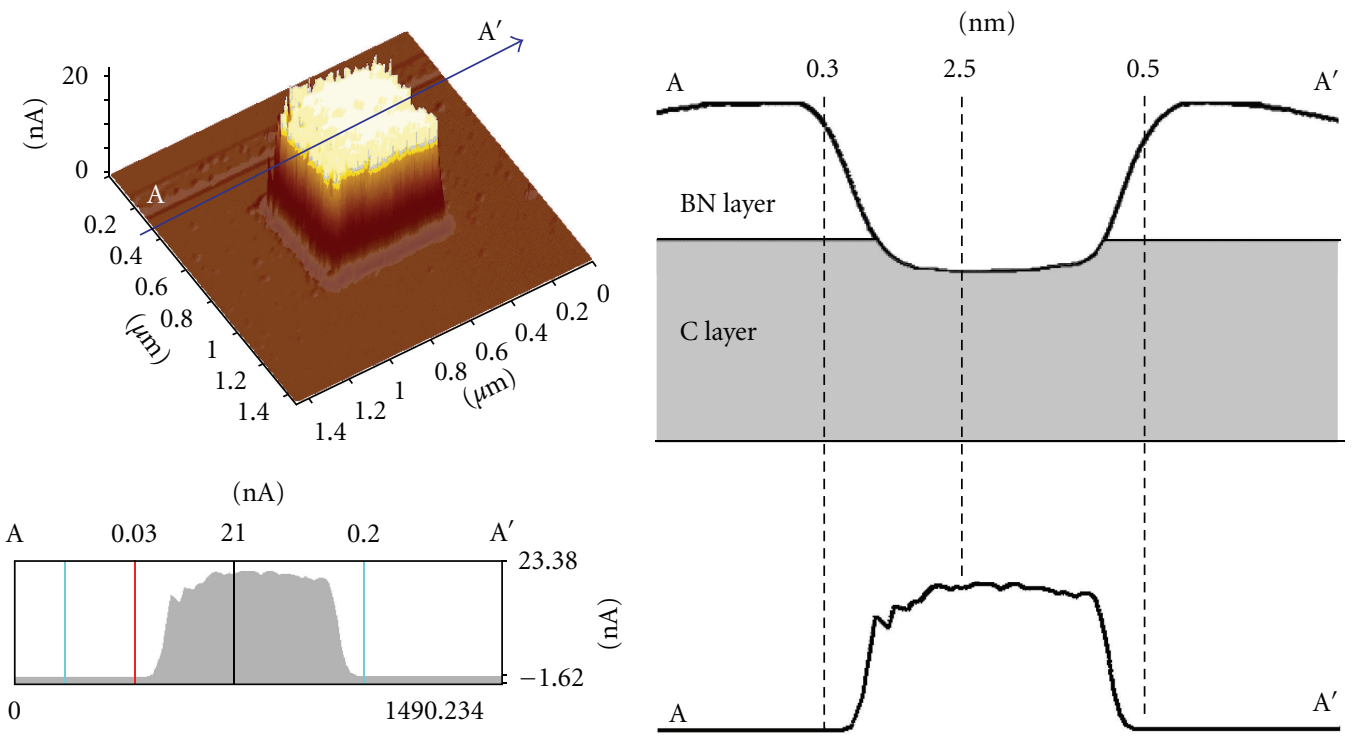

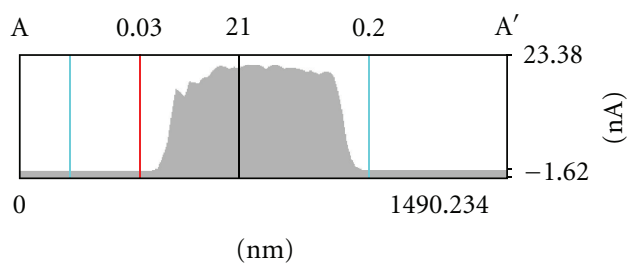

(a) Topographic image of current

(b) Cross-section profile of current distribution

FIGURE 17: (a) Profile and cross-sectional images of current distribution and (b) mode of current versus wear track for 4-nm-period (B/CN)n film at $1000 \mathrm{nN}$ load and vibration amplitude of $20 \mathrm{~nm}$.

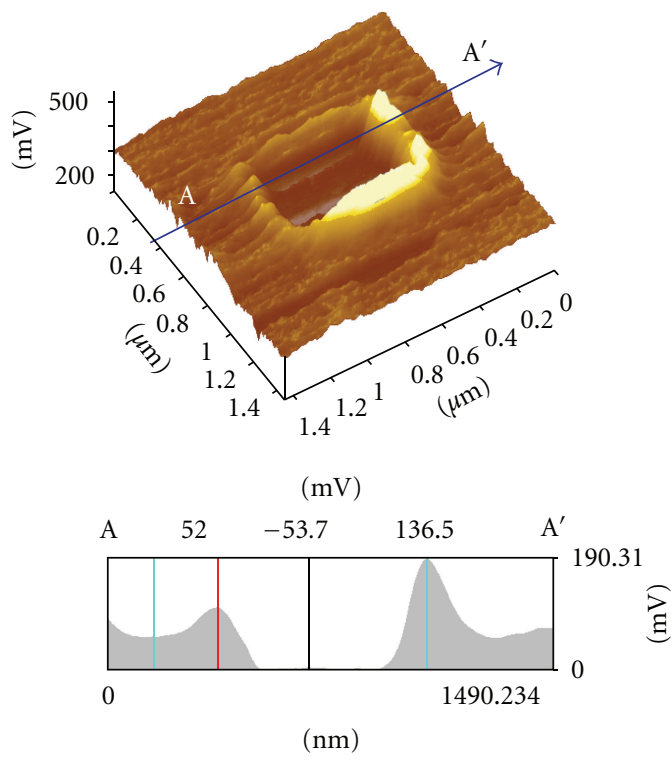

(a) Topographic image of friction

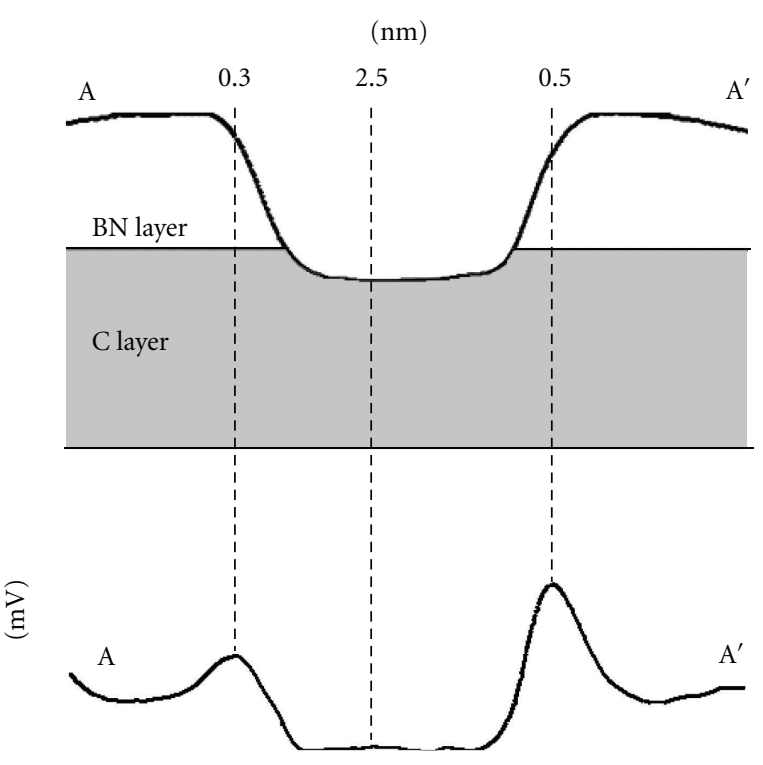

(b) Cross-section profile of friction distribution

Figure 18: (a) Profile and cross-sectional images of friction distribution and (b) model of friction versus wear track for 4-nm-period (BN/C)n film at $1000 \mathrm{nN}$ load and vibration amplitude of $20 \mathrm{~nm}$.

it is considered that the $\mathrm{C}$ layer has higher conductivity and lower friction than the BN layer.

\section{Conclusions}

In this paper, we reported the research on the nanoprocessing and characterization of nanoperiod multilayers using an AFM. Nanoperiod multilayer films were deposited by bias sputtering and nanoprocessing and then the film were characterized.

Nanoperiod multilayer $(\mathrm{CN} / \mathrm{BN}) \mathrm{n}$ and $(\mathrm{BN} / \mathrm{CN}) \mathrm{n}$ films with top $\mathrm{CN}$ and $\mathrm{BN}$ layers, respectively, were deposited by $\mathrm{RF}$ sputtering. The nanoindentation hardness, modulus of dissipation energy, and nanometer-scale wear depth of the 4-nm-period multilayer $(\mathrm{CN} / \mathrm{BN}) \mathrm{n}$ film were the highest, lowest, and lowest among the films examined, respectively; therefore, the mechanical properties are clearly superior for 

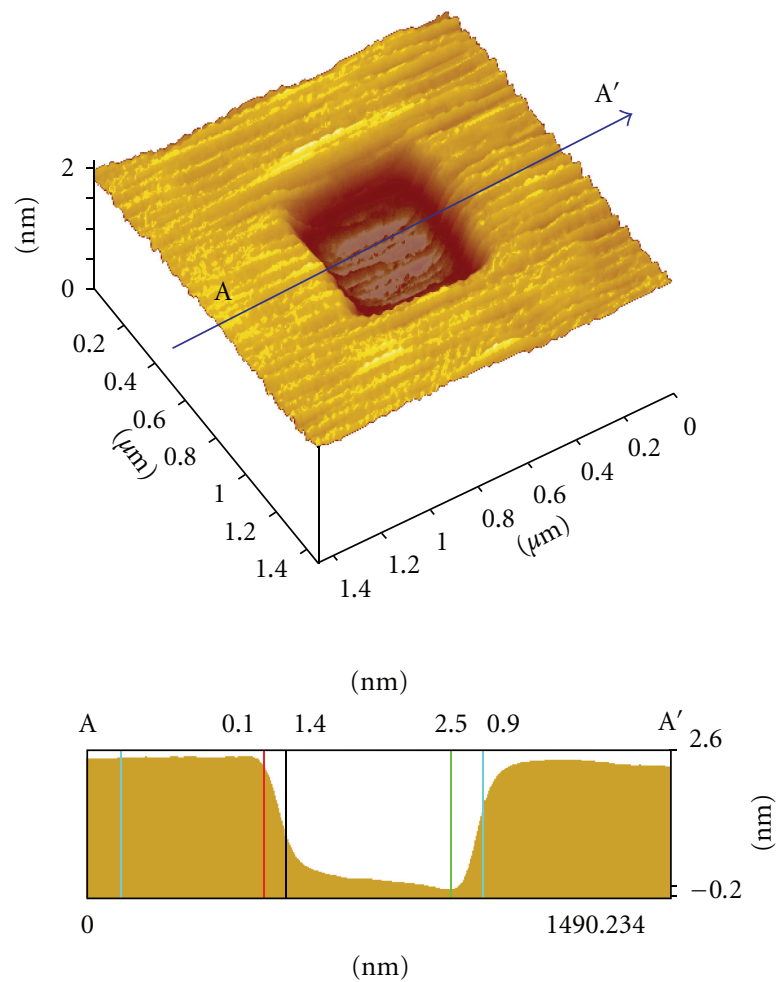

Figure 19: Profile and cross-sectional images of 4-nm-period (C/BN)n topography at $3500 \mathrm{nN}$ load.

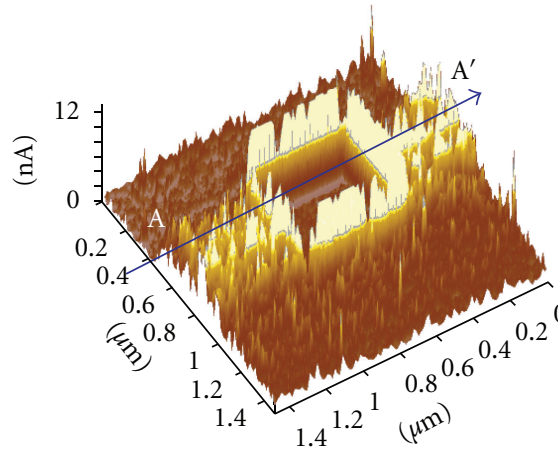

$(\mathrm{nA})$
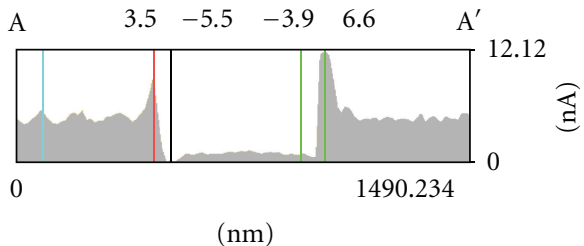

(a) Topographic image of current

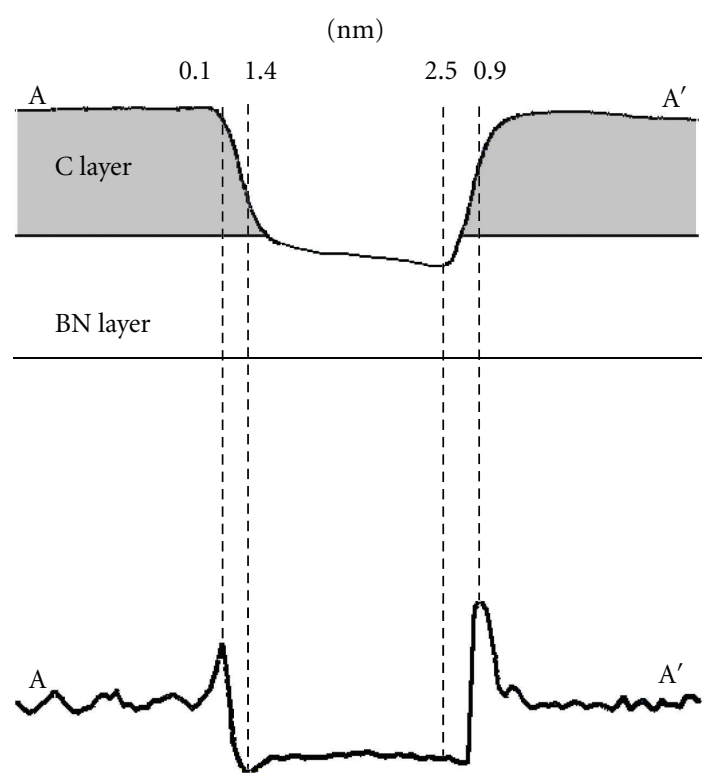

(b) Cross-section profile of current distribution

Figure 20: (a) Profile and cross-sectional images of current distribution and (b) model of current versus wear track for 4-nm-period $(\mathrm{C} / \mathrm{BN}) \mathrm{n}$ film at $3500 \mathrm{nN}$.

this film. The nanoindentation hardness and wear resistance of the nanoperiod multilayer $(\mathrm{CN} / \mathrm{BN}) \mathrm{n}$ films were superior to those of $(\mathrm{BN} / \mathrm{CN}) \mathrm{n}$ films because of the higher strength of the $\mathrm{CN}$ top layer of the $(\mathrm{CN} / \mathrm{BN}) \mathrm{n}$ film than the $\mathrm{BN}$ top layer of (BN/CN)n films. The weak BN layer was easily fractured.
Because of the prevention of fracture growth at the interface between layers of the multilayer films, we proposed the nanometer-scale mechanical processing of multilayer films by applying this wear mechanism, and the layer-by-layer nanoprocessing of multilayer films was realized. 


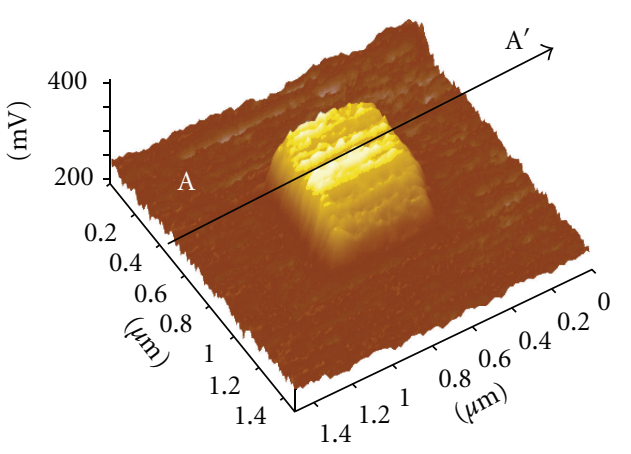

$(\mathrm{mV})$

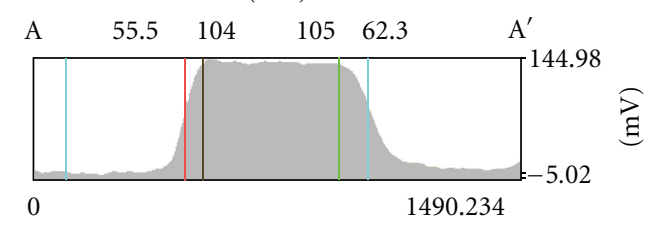

$(\mathrm{nm})$

(a) Topographic image of friction

$(\mathrm{nm})$

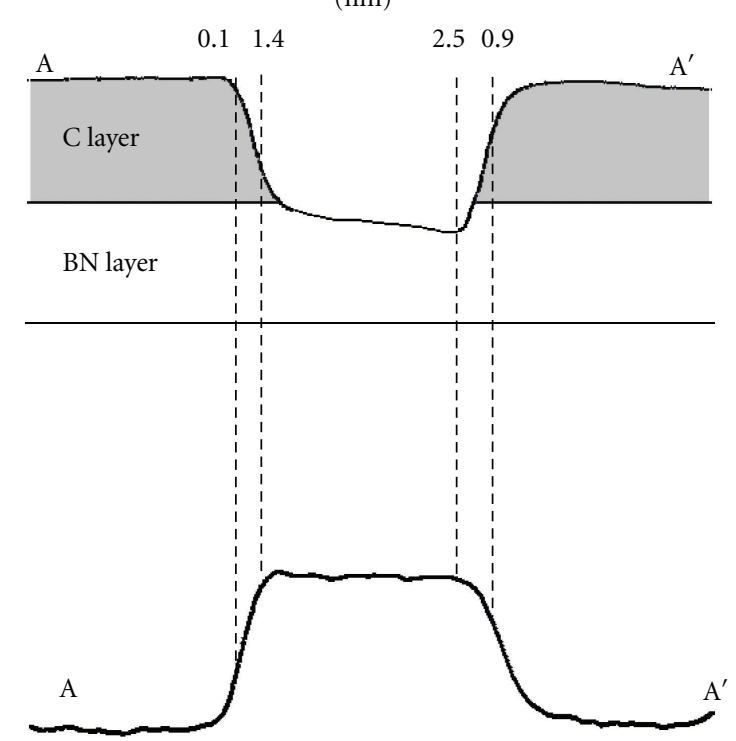

(b) Cross-section profile of friction distribution

Figure 21: (a) Profile and cross-sectional images of friction distribution and (b) model of friction versus wear track for 4-nmperiod $(\mathrm{C} / \mathrm{BN}) \mathrm{n}$ film at $3500 \mathrm{nN}$ load.

The processing of 4-nm-period (BN/C)n and (C/BN)n multilayer films using an AFM with a conductive B-doped CVD-diamond-coated silicon tip applied at loads from 500 to $4000 \mathrm{nN}$ was found to be possible. The results of wear tests show that less wear occurs at a $\mathrm{C}$ layer than at a $\mathrm{BN}$ layer. It was experimentally confirmed that the $\mathrm{C}$ layer has higher conductivity and lower frictional force than a $\mathrm{BN}$ layer. Furthermore, at wear depths ranging between 2.0 and $2.5 \mathrm{~nm}$, the current flow decreased and the frictional force increased owing to a mixed layer (interface) between the $\mathrm{C}$ layer and BN layer. Therefore, the conductive AFM enabled the characterization of processed areas at $\mathrm{C}$ and/or $\mathrm{BN}$ layers by measuring the current and friction distributions. This method also provided a new insight into the physical and electrical processes occurring at nanostructural surfaces, particularly in multilayered films.

\section{Acknowledgment}

This research was partly supported by a Grant-in-Aid to the Scientific Research Foundation from the Ministry of Education Culture, Sports, Science and Technology of Japan (B21360076).

\section{References}

[1] X. Chu, M. Wong, S. Sproul, W. D. Rhode, and S. A. Barnett, "Deposition and properties of polycrystalline TiN/NbN superlattice coatings," Journal of Vacuum Science \& Technology A, vol. 10, no. 1604, 6 pages, 1992.

[2] L. A. Donohue, J. Cawley, D. B. Lewis, J. S. Brooks, and W. D. Munz, "Investigation of superlattice coatings deposited by a combined steered arc evaporation and unbalanced magnetron sputtering technique," Surface and Coatings Technology, vol. 76-77, no. 1, pp. 149-158, 1995.

[3] X. Chu and S. A. Barnett, "Model of superlattice yield stress and hardness enhancements," Journal of Applied Physics, vol. 77, no. 9, pp. 4403-4411, 1995.

[4] S. Miyake, "Improvement of mechanical properties of nanometer period multilayer films at interfaces of each layer," Journal of Vacuum Science and Technology B, vol. 21, no. 2, pp. 785-789, 2003.

[5] D. Li, X. Chu, S. C. Cheng et al., "Synthesis of superhard carbon nitride composite coatings," Applied Physics Letters, vol. 67, p. 203, 1995.

[6] A. Nakayama, "A mystery of superlattice thin film hardness," Japan Society Mechanical Engineering, vol. 100, no. 943, pp. 593-595, 1997 (Japanese).

[7] S. Miyake, R. Kaneko, Y. Kikuya, and I. Sugimoto, "Microtribological studies on fluorinated carbon film," Transactions of the American Society of Mechanical Engineers, Journal of Tribology, no. 113, pp. 384-389, 1991.

[8] S. Miyake, T. Miyamoto, R. Kaneko, and T. Miyazaki, "Macro and microtribological properties of polished CVD diamond films and trial laserprocessing of diamond," The Institute of Electronics, Information and Communication Engineers, on Electronics, vol. E78 C, no. 2, pp. 180-185, 1995.

[9] S. Miyake, R. Kaneko, and T. Miyamoto, "Micro wear Increasing of polished chemically vapour deposited diamond film by nitrogen ion implantation by atomic force microscope," Nuclear Instruments and Methods in Physics Research Section B, vol. 108, pp. 70-74, 1996.

[10] S. Miyake, S. Watanabe, H. Miyazawa, M. Murakawa, R. Kaneko, and T. Miyamoto, "Micro scratch hardness increasing of ion plated carbon film by nitrogen inclusion evaluated by atomic force microscope," Applied Physics Letters, vol. 65, no. 25, pp. 3206-3208, 1994.

[11] S. Miyake, S. Watanabe, M. Murakawa, R. Kaneko, and T. Miyato, "Tribological study of cubic boron nitride film," Thin Solid Films, vol. 212, no. 1-2, pp. 262-266, 1992.

[12] S. Miyake and K. Matsuzaki, "Mechanical nanoprocessing of layered crystal structure materials by atomic force microscopy," Japanese Journal of Applied Physics, vol. 41, no. 9, pp. 5706-5712, 2002. 
[13] S. Miyake, Y. Sekine, and S. Watanabe, "Deposition and tribology of carbon and boron nitride super lattice solid lubricant films," The Japan Society of Mechanical Engineers International Journal C, vol. 47, pp. 377-383, 2004.

[14] S. Miyake, "Tribology of carbon nitride and boron nitride nanoperiod multilayer films and its application to nanoscale processing," Thin Solid Films, vol. 493, no. 1-2, pp. 160-169, 2005.

[15] H. J. Mamin, L. S. Fan, S. Hoen, and D. Rugar, "Tip-based data storage using micromechanical cantilevers," Sensors and Actuators, vol. 48, no. 3, pp. 215-219, 1995.

[16] H. J. Mamin and D. Rugar, "Thermomechanical data storage using a fiber optic stylus," Applied Physics Letters, vol. 61, no. 24, p. 1003, 1992.

[17] G. Binnig, M. Despont, U. Drechsler et al., "Ultrahigh-density atomic force microscopy data storage with erase capability," Applied Physics Letters, vol. 74, no. 9, pp. 1329-1331, 1999.

[18] S. Miyake and J. Kim, "Nanoprocessing of carbon and boron nitride nanoperiod multilayer films," Japanese Journal of Applied Physics, vol. 42, no. 3 B, pp. L322-L325, 2003.

[19] L. Zhang, T. Sakai, N. Sakuma, T. Ono, and K. Nakayama, "Nanostructural conductivity and surface-potential study of low-field-emission carbon films with conductive scanning probe microscopy," Applied Physics Letters, vol. 75, no. 22, pp. 3527-3529, 1999.

[20] M. Nonnenmacher, M. P. O’Boyle, and H. K. Wickramasinghe, "Kelvin probe force microscopy," Applied Physics Letters, vol. 58, no. 25, pp. 2921-2923, 1991.

[21] A. Kumagai, K. Harada, K. Ozawa, and O. Ishiwata, "Evaluation of tribological properties of a longitudinal magnetic recording medium using lateral modulation friction force microscope," Japanese Journal of Applied Physics, vol. 35, no. 12 A, pp. 6286-6291, 1996.

[22] S. Miyake, Y. Takahashi, M. Wang, T. Saitoh, and S. Matsunuma, "Lubricant supply from crystal boundaries of perpendicular magnetic disk evaluated by lateral modulation friction force microscopy," Japanese Journal of Applied Physics, vol. 43, no. 11 B, pp. L1469-L1471, 2004.

[23] S. Miyake and M. Wang, "Mechanical properties of extremely thin B-C-N protective layer deposited with helium addition," Japanese Journal of Applied Physics, vol. 43, no. 6 A, pp. 35663571, 2004.

[24] M. F. Doerner and W. D. Nix, "A method of interpreting the data from depth-sensing indentation instruments," Journal of Materials Research, vol. 14, pp. 601-609, 1986.

[25] Z. N. Farhat, Y. Ding, D. O. Northwood, and A. T. Alpas, "Nanoindentation and friction studies on Ti-based nanolaminated films," Surface and Coatings Technology, vol. 89, no. 1-2, pp. 24-30, 1997.

[26] K. Yamanaka and E. Tomita, "Lateral force modulation atomic force microscope for selective imaging of friction forces," Japanese Journal of Applied Physics, vol. 34, no. 5 B, pp. 2879 2882, 1995.

[27] S. Miyake, M. Wang, T. Saitoh, and S. Watanabe, "Microtribological properties of B-C-N extremely thin protective films deposited on plasma pretreated magnetic layers," Surface and Coatings Technology, vol. 195, no. 2-3, pp. 214-226, 2005.

[28] J. Colchero, M. Luna, and A. M. Baró, "Lock-in technique for measuring friction on a nanometer scale," Applied Physics Letters, vol. 68, no. 20, pp. 2896-2898, 1996.

[29] O. Pfeiffer, R. Bennewitz, A. Baratoff, E. Meyer, and P. Grütter, "Lateral-force measurements in dynamic force microscopy," Physical Review B, vol. 65, no. 16, Article ID 161403, pp. 1614031-1614034, 2002.
[30] S. Miyake, Y. Wakatsuki, M. Wang, and S. Matsunuma, "Amplitude dependence of the lateral-vibration wear test for perpendicular recording magnetic disks treated by heat curing," Japanese Journal of Applied Physics, vol. 44, no. 5 A, pp. 3209-3217, 2005.

[31] S. Miyake, T. Hashizume, and Y. Wakatsuki, "Nanoprocessing and evaluation of carbon and boron nitride nanoperiod multilayer films by lateral force modulation method," Surface and Interface Analysis, vol. 38, no. 4, pp. 873-878, 2006.

[32] S. Miyake, Y. Takahashi, M. Wang, and T. Saito, "Durability evaluation of perfluoropolyether-lubricant-coated protective diamond-like carbon film by the lateral vibration friction test," Journal of Physics D, vol. 38, no. 13, pp. 2244-2252, 2005.

[33] S. Miyake, M. Wang, and J. Kim, "Investigation of microelectro-mechanical processing characteristics of layered boron nitride and carbon films," Nanotechnology, vol. 17, pp. 16071614, 2006. 

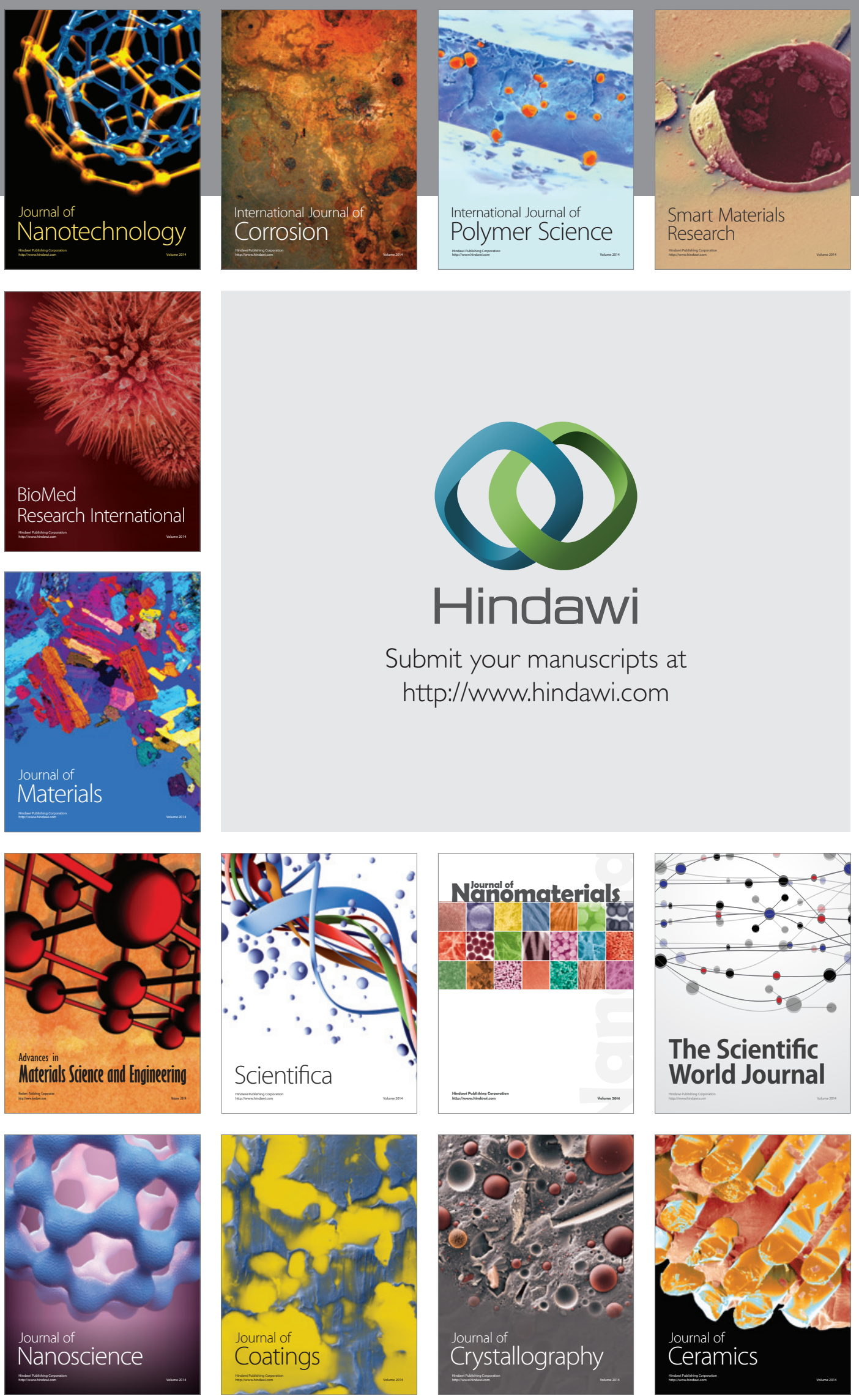

The Scientific World Journal

Submit your manuscripts at

http://www.hindawi.com

\section{World Journal}

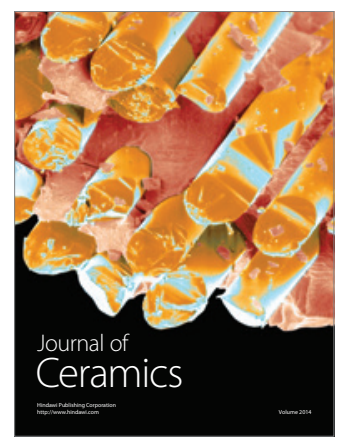

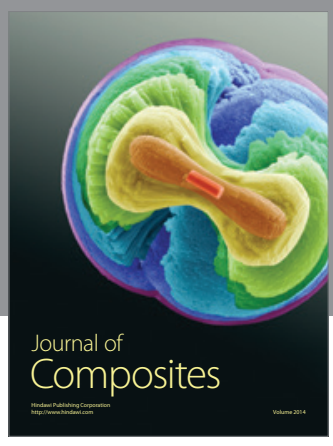
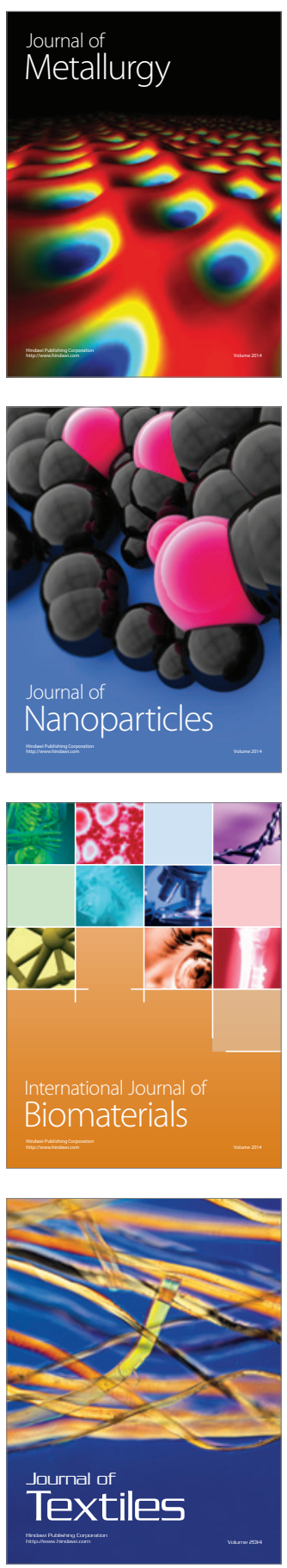